\title{
RESEARCH
}

Open Access

\section{Triiodothyronine modulates neuronal plasticity mechanisms to enhance functional outcome after stroke}

\author{
Daniela Talhada 1,2, Joana Feiteiro², Ana Raquel Costa², Tiago Talhada', Elisa Cairrão², Tadeusz Wieloch', \\ Elisabet Englund ${ }^{3}$, Cecília Reis Santos ${ }^{2}$, Isabel Gonçalves ${ }^{2}$ and Karsten Ruscher ${ }^{1,4^{*}}$ (D)
}

\begin{abstract}
The development of new therapeutic approaches for stroke patients requires a detailed understanding of the mechanisms that enhance recovery of lost neurological functions. The efficacy to enhance homeostatic mechanisms during the first weeks after stroke will influence functional outcome. Thyroid hormones (TH) are essential regulators of neuronal plasticity, however, their role in recovery related mechanisms of neuronal plasticity after stroke remains unknown. This study addresses important findings of 3,5,3'-triiodo-L-thyronine $\left(T_{3}\right)$ in the regulation of homeostatic mechanisms that adjust excitability inhibition ratio in the post-ischemic brain. This is valid during the first 2 weeks after experimental stroke induced by photothrombosis (PT) and in cultured neurons subjected to an in vitro model of acute cerebral ischemia. In the human post-stroke brain, we assessed the expression pattern of TH receptors (TR) protein levels, important for mediating $\mathrm{T}_{3}$ actions. Our results show that $T_{3}$ modulates several plasticity mechanisms that may operate on different temporal and spatial scales as compensatory mechanisms to assure appropriate synaptic neurotransmission. We have shown in vivo that long-term administration of $\mathrm{T}_{3}$ after PT significantly (1) enhances lost sensorimotor function; (2) increases levels of synaptotagmin 1\&2 and levels of the post-synaptic GluR2 subunit in AMPA receptors in the peri-infarct area; (3) increases dendritic spine density in the peri-infarct and contralateral region and (4) decreases tonic GABAergic signaling in the peri-infarct area by a reduced number of parvalbumin ${ }^{+}$/ c-fos ${ }^{+}$neurons and glutamic acid decarboxylase 65/67 levels. In addition, we have shown that $\mathrm{T}_{3}$ modulates in vitro neuron membrane properties with the balance of inward glutamate ligand-gated channels currents and decreases synaptotagmin levels in conditions of deprived oxygen and glucose. Interestingly, we found increased levels of TRß1 in the infarct core of post-mortem human stroke patients, which mediate $T_{3}$ actions. Summarizing, our data identify $T_{3}$ as a potential key therapeutic agent to enhance recovery of lost neurological functions after ischemic stroke.
\end{abstract}

Keywords: Ischemia, Photothrombosis, Recovery, Stroke, Thyroid hormones, Thyroid hormone receptors, 3,5,3'-triiodo-Lthyronine $\left(T_{3}\right), 3,5,3^{\prime}, 5^{\prime}$-tetraiodo-L-thyronine $\left(T_{4}\right)$

\footnotetext{
* Correspondence: karsten.ruscher@med.lu.se

'Laboratory for Experimental Brain Research, Division of Neurosurgery, Department of Clinical Sciences, Lund University, BMC A13, S-22184 Lund, Sweden

${ }^{4}$ LUBIN Lab - Lunds Laboratorium för Neurokirurgisk Hjärnskadeforskning, Division of Neurosurgery, Department of Clinical Sciences, Lund University, Lund, Sweden Full list of author information is available at the end of the article
}

(c) The Author(s). 2020 Open Access This article is licensed under a Creative Commons Attribution 4.0 International License, which permits use, sharing, adaptation, distribution and reproduction in any medium or format, as long as you give appropriate credit to the original author(s) and the source, provide a link to the Creative Commons licence, and indicate if changes were made. The images or other third party material in this article are included in the article's Creative Commons licence, unless indicated otherwise in a credit line to the material. If material is not included in the article's Creative Commons licence and your intended use is not permitted by statutory regulation or exceeds the permitted use, you will need to obtain permission directly from the copyright holder. To view a copy of this licence, visit http://creativecommons.org/licenses/by/4.0/ The Creative Commons Public Domain Dedication waiver (http://creativecommons.org/publicdomain/zero/1.0/) applies to the data made available in this article, unless otherwise stated in a credit line to the data. 


\section{Introduction}

Loss of motor function following ischemic stroke is the most enduring and disabling consequence $[4,26]$. Despite the attempt to find neuroprotective treatments that mitigate tissue damage and loss of motor function, their translation into clinical practice has been disappointing. So far, thrombectomy and thrombolysis in the acute phase after stroke are the only effective treatments to restore blood flow and minimize brain damage. However, acute therapies are limited to the first $4.5 \mathrm{~h}$ for thrombolysis or up to $24 \mathrm{~h}$ for thrombectomy after stroke onset and are accessible to less than $10 \%$ of stroke patients $[36,49]$. Beyond the acute phase constant and consistent specific rehabilitation programs are instrumental to partially regain brain function, dependent on size and brain regions affected by stroke [37]. Therefore, the options to minimize the damage after ischemic stroke remains sub-optimal and there is need for new therapeutic approaches that target restorative processes.

In response to loss of input from the infarct core, surviving neurons adopt self-repair and self-organizing homeostatic mechanisms in order to stabilize the ratio between excitatory and inhibitory circuits and maintain adequate synaptic input [21]. First, blood flow is restored and there is a temporary resolution in neuronal activity and metabolism in regions surrounding and connected to the infarct $[33,82]$. Concomitantly, in response to cell death in the infarct core, there is a change in neuronal pathways and reorganization of neuronal connectivity, namely axonal growth, spine remodeling and dendritic arborization [29, 82]. A wide variety of homeostatic mechanisms contribute to the maintenance of overall excitability, involving the regulation of neuronal intrinsic excitability and synaptic transmission. These mechanisms include changes in receptor expression at the post-synaptic level, neurotransmitter release at the presynaptic level, ion channel function and synapse number or synaptic strength $[52,76,77]$.

Processes of neuronal reorganization and cellular responses to the infarct occur during the first weeks after stroke in mice [7] and up to months and years in humans $[23,24]$. During this period the brain is highly plastic, and distinct overlapping events promoting recovery of neurological function can be modulated by external interventions [82]. Therefore, current research is focused to understand mechanisms of post-injury plasticity that occur spontaneously after stroke [50, 82].

Current epidemiological human studies suggest that thyroid hormones $(\mathrm{TH})$ signaling is related to a better outcome after stroke although the mechanisms involved are poorly investigated [71]. Several studies have pointed out that TH contribute to neuroprotection when administered before $[46,61]$ or during the first hours after stroke or traumatic brain injury $[20,22,27,40,55]$. TH also protect cortical neurons against glutamate-induced neuronal damage [42].

However, long-term effects of $\mathrm{TH}$ during the recovery phase after stroke remain largely unknown [71]. Here we hypothesized that $3,5,3^{\prime}, 5^{\prime}$-tetraiodo-L-thyronine $\left(\mathrm{T}_{4}\right)$ and 3,5,3' -triiodo-L-thyronine $\left(\mathrm{T}_{3}\right)$ might be actively involved to enhance post-stroke recovery, since they are essential in several mechanisms for brain development $[3,5]$ and normal function of the adult brain [47]. Summarizing, $\mathrm{TH}$ are involved in mechanisms of neuronal proliferation, migration and differentiation, neurite outgrowth, synaptic plasticity, dendritic branching and myelination during brain development $[5,28]$. In the adult brain, several processes of neurorepair are particularly dependent on $\mathrm{T}_{3}$ action, namely neuronal plasticity and neurogenesis $[35,56]$.

To study the role of $\mathrm{TH}$ in mechanisms of neuronal repair, we analyzed post-ischemic brains of mice subjected to intraperitoneal (i.p.) administration of $\mathrm{T}_{4}$ and $\mathrm{T}_{3}$ at 5 or $50 \mu \mathrm{g} / \mathrm{kg}$ starting at day two after photothrombosis (PT) and every second day, in a total of six administrations; we assessed $\mathrm{T}_{3}$ effects in ionotropic glutamate receptors (iGluRs) in cultured glutamatergic neurons; and we analyzed expression pattern of $\mathrm{TH}$ receptors (TR) alpha $1(\mathrm{TR} \alpha 1)$ and beta $1(\mathrm{TR} \beta 1)$ in post-ischemic brains of mice and human patients. In the present investigation we demonstrate that $\mathrm{T}_{3}$ modulates pathways during critical periods of recovery after stroke involved in reorganization of neuronal circuits and synaptic plasticity, functional connectivity and motor recovery. Summarizing, we demonstrate that (1) $\mathrm{T}_{3}$ enhanced recovery of lost motor function in an experimental model of stroke, (2) $\mathrm{T}_{3}$ increased levels of synaptotagmin $1 \& 2$ and levels of post-synaptic glutamate receptor 2 (GluR2) subunit in alpha-amino-3-hydroxy-5-methyl-4isoxazolepropionic acid (AMPA) receptors in the periinfarct area, (3) $\mathrm{T}_{3}$ increased dendritic spine density in the ipsilateral and contralateral regions and (4) $\mathrm{T}_{3}$ decreased tonic GABAergic signaling in the peri-infarct area by a reduced number of parvalbumin-positive $\left(\mathrm{PV}^{+}\right) /$ C-fos $^{+}$neurons and glutamic acid decarboxylase 65/67 (GAD 65/67) protein levels. In cultured neurons (5) $\mathrm{T}_{3}$ modulates membrane properties with the balance of inward glutamate ligand-gated channels currents and (6) $\mathrm{T}_{3}$ modulates synaptotagmin levels in an in vitro model of ischemia. In the human post-ischemic brain (7) TR $\beta 1$ has a spatial expression pattern, which may drive $T_{3}$ transcriptional activity.

\section{Materials and methods}

\section{Ethical considerations}

Mice were bred and genotyped at the conventional facility of the Biomedical Centre, (BMC, Lund, Sweden). All animal experiments (Studies I and II) were carried out 
in accordance with the international guidelines on experimental animal research, with the approval of the Malmö-Lund Ethical Committee (ethical permit no. M50/2015) and followed the ARRIVE guidelines. All in vitro experiments (Study III) were carried out in compliance with directives on animal experimentation (Decreto-Lei 113/2013 and 2010/63/EU) in Portugal and European Union and with approval of the committee of Animal Research at Universidade da Beira Interior (CICS-UBI, Covilhã, Portugal). Human brain tissue used in this study was used with the approval of the Lund Ethical Review Board for research involving humans (Dnr 2011/80).

\section{Thyroid hormones effects after experimental stroke (study I)}

For this study, 117 C57BL/6 male mice (20 to $26 \mathrm{~g}$, aged 9 to 10 weeks, purchased from Charles River) were used. Out of 117 animals, 12 were excluded due to problems during surgery and mortality before entering the treatment phase and 105 animals were randomly assigned into the treatment groups (Fig. 1). Treatment was initiated on day two after PT and every other day until the endpoint of the study. Vehicle ( $\mathrm{Vh}, \mathrm{NaCl} 0.9 \%), \mathrm{T}_{3}$ (5 or $50 \mu \mathrm{g} / \mathrm{kg}$ ) or $\mathrm{T}_{4}(5$ or $50 \mu \mathrm{g} / \mathrm{kg})$ were administered by i.p. injection in a total of six administrations. On days two, seven and 14 after stroke onset or sham surgery, animals were evaluated for motor function.

\section{Photothrombosis}

Focal ischemic stroke was induced by $\mathrm{PT}$, as described previously $[65,81]$. Ischemic stroke was induced in the right hemisphere through illumination of a squared aperture measuring 4.0 to $2.0 \mathrm{~mm}$ (equal to an area of $\left.8.0 \mathrm{~mm}^{2}\right)$. The light position related to bregma $(+1.5$ $\mathrm{mm}$ lateral and $+0.5 \mathrm{~mm}$ anterior) affected the mouse primary motor cortex of forelimb-responsive sites, in the left body side [72]. The same procedure was performed in sham operated animals, with saline injection instead of photosensitizing dye.

\section{Behavior analysis}

Motor function and exploratory behavior after TH treatment was assessed using a neuroscore consisting of the rotating pole test (RPT) and the open field test, respectively $[60,79]$. These assessments were performed in a blinded fashion to the investigator that performed the surgeries and treatments.

The RPT was used to assess postural and locomotor asymmetry that results from an unilateral brain lesion [57]. After stroke or sham surgery, animals were evaluated on day two for randomization into treatment groups. Each trial was video recorded, and videos were used to assess motor dysfunction by using a zero to six scoring system (Table 1). Animals that did not fulfill inclusion criteria were excluded from behavior analysis (see Additional file 1: Supplementary methods).

The open field test was performed 14 days after stroke to assess both spontaneous post-ischemic locomotor activity and post-ischemic exploration behavior [78].

\section{Immunohistochemistry and immunofluorescence}

Tissue collection for immunostainings was performed as described before $[53,63]$. Primary antibodies used for immunofluorescence were rabbit TR $\beta 1$ (Millipore, 1: 1000), rabbit TR $\alpha 1$ (Abcam, 1:1000), goat parvalbumin (PV235, Swant, 1:5000), mouse neuronal nuclei (NeuN, Millipore, 1:1000), glial fibrillary acidic protein (GFAP)Cy3 (Sigma, 1:5000), rat cluster of differentiation (CD) 68 (Abd Serotec, 1:300), and mouse glutathione Stransferase (GST)-pi isoform (BD Transduction Laboratories, 1:1000).

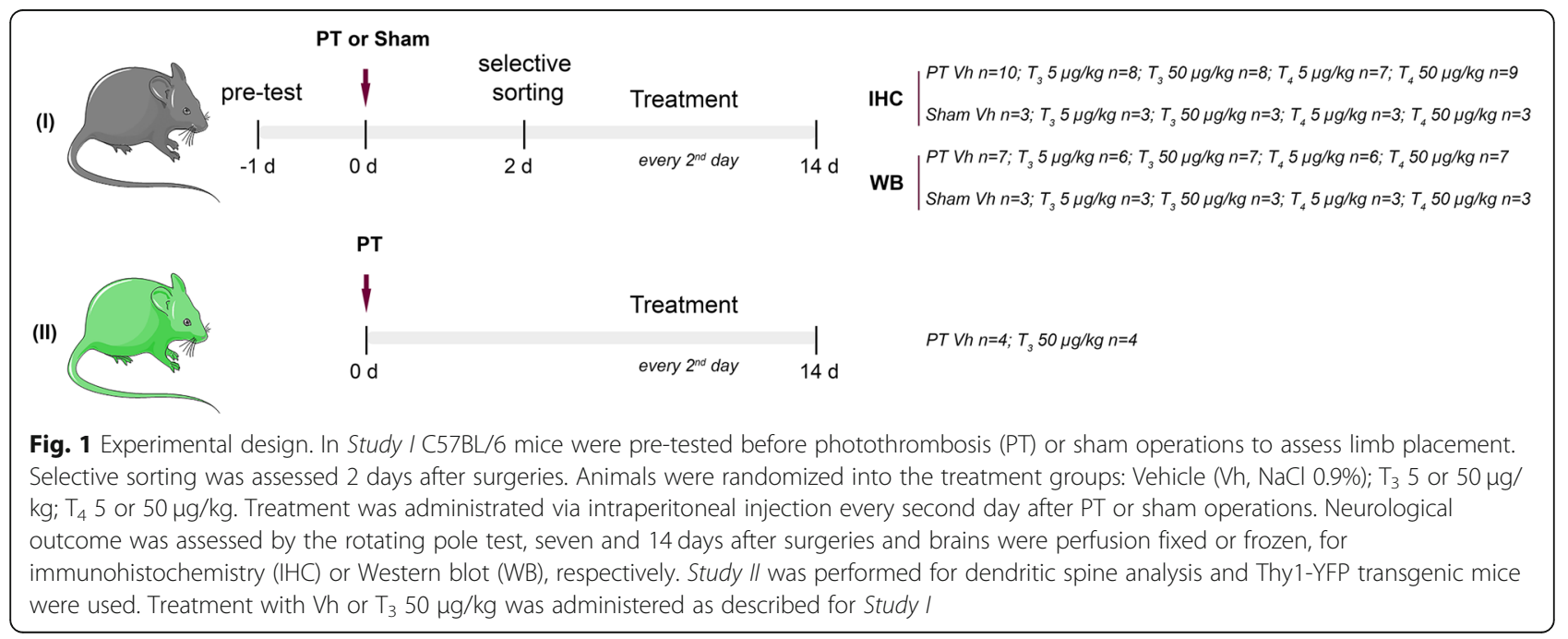


Table 1 Motor function assessed by the rotating pole test before and after photothrombosis at days 2, 7 and 14

\begin{tabular}{ll}
\hline Score & Criteria \\
\hline 0 & $\begin{array}{l}\text { animal falls off immediately upon entry onto the pole } \\
\text { animal remains embraced to the pole unable to cross and } \\
\text { eventually falls off the pole }\end{array}$ \\
$2 \quad \begin{array}{l}\text { animal falls off during crossing or if the hindlimbs do not } \\
\text { contribute to forward movement }\end{array}$ \\
$\begin{array}{l}\text { animal crosses the pole while continuously slipping with the } \\
\text { forelimbs or hindlimbs }\end{array}$ \\
$\begin{array}{l}\text { animal crosses pole with }>3 \mathrm{ft} \text { slips } \\
6\end{array} \quad \begin{array}{l}\text { animal traverses the pole with } 1-3 \mathrm{ft} \text { slips } \\
\text { animal crosses the pole without any foot slips }\end{array}$ \\
\hline
\end{tabular}

\section{Infarct size measurement}

Coronal brain sections from the start until the end of the infarct and spaced one millimeter were collected and stained for NeuN (rabbit NeuN, Millipore, 1:5000). The non-injured portion of the ipsilateral and contralateral hemisphere were encircled and the indirect infarct volume was calculated by integration of areas from serial sections of each brain as described previously [70] using Fiji software [64].

\section{Counting of parvalbumin positive cells}

For each animal one coronal section $(-2.0 \mathrm{~mm}$ relative to bregma) was stained for $\mathrm{PV}^{+}$neurons using a monoclonal goat primary antibody (PV235, Swant, 1: 5000), and visualization accessed using a VECTOR NovaRED Peroxidase (HRP) Substrate Kit (Vector Laboratories, CA, USA). Rabbit c-fos (Santa Cruz, 1:500) positive immunoreactivity $\left(c-\right.$ fos $\left.^{+}\right)$was accessed using the avidin-biotin-HRP system.

\section{Immunoblotting}

Brains from mice were collected as previously described [63] and the tissue correspondent to the infarct core and peri-infarct was collected. Tissue from human brains were dissected out by a pathologist following autopsy. Primary antibodies used for Western blots were rabbit TR $\alpha 1$ (Abcam, 1:1000), rabbit TR $\beta 1$ (Millipore, 1:20000), mouse postsynaptic protein 95 (PSD95; BD Transduction Laboratories, 1:1000), rabbit synaptophysin (Thermoscientific, 1:15000), rabbit GluR1 (Millipore, 1:2000), mouse GluR2 (Millipore, 1:1000), mouse N-methyl-D-aspartate receptor 1 (NMDAR1) (BD Transduction Laboratories, 1:1000), rabbit synaptotagmin 1\&2 (Abcam, 1:1000) and rabbit GAD 65/67 (Millipore, 1:2000). Membranes were reprobed with anti $\beta$-actin HRP conjugated (1:150000, Sigma-Aldrich). Levels were calculated as a percentage of $\beta$-actin expression, after densitometric analysis using Fiji software.
Dynamics of dendritic spines after administration with $\mathrm{T}_{3}$ (study II)

To study the effects of $\mathrm{T}_{3}$ on dendritic spine dynamics in mouse neocortical neurons after experimental stroke, eight Thy1-yellow fluorescent protein (YFP) transgenic mice (25 to $40 \mathrm{~g}$, aged 1 year, own breeding), that express YFP in neuronal population were used. Mice were randomly assigned in the following treatment groups: PT/Vh, $n=4 ; \mathrm{PT} / \mathrm{T}_{3} 50 \mu \mathrm{g} / \mathrm{kg}, n=4$ (Fig. 1). Treatment was administered as described above for Study I. Fourteen days after the surgery, mice were sacrificed, perfusion fixed with paraformaldehyde $4 \%$ and brains were collected for further infarct volume assessment and dendritic spine analysis.

\section{Photothrombosis}

To induce PT in animals for dendritic spine analysis (Study II) the surgical procedure was performed as in Study I, and the left hemisphere was illuminated with a cold light source through a round aperture measuring $1.5 \mathrm{~mm}$ in diameter (equal to an area of $1.767 \mathrm{~mm}^{2}$ ) for $20 \mathrm{~min}$. This approach induced smaller infarct sizes so that dendritic spines could be analyzed in different regions in the peri-infarct area. The same procedure was performed in Sham operated animals, with saline injection instead of photosensitizing dye.

\section{Detection and classification of dendritic spines from fluorescence laser scanning microscopy}

Three coronal sections per animal were collected at different levels: $+2.0 \mathrm{~mm},+1.0 \mathrm{~mm}$ and $0 \mathrm{~mm}$ relatively to bregma, corresponding to the rostral pole, center and caudal pole of the infarct, respectively. For each animal, we analyzed layers II/III correspondent to the apical pyramidal neurons in the ipsilateral motor cortex (Region 1, R1), ipsilateral somatosensory cortex (Region 2, R2), contralateral motor cortex (Region 3, R3) and contralateral somatosensory cortex (Region 4, R4).

Dendritic spine density and shape classification was accurately quantified and characterized using a threedimensional computational approach as previously described, after image deconvolution [58].

For each region, three to five dendritic branches were randomly selected. Dendrites were manually selected, and spines were automatically detected using NeuronStudio software. Dendritic spines were classified according to the head to neck ratio and head diameter as stubby, mushroom or thin $[30,58]$, using default parameters from NeuronStudio. Dendritic spine density was calculated with the ratio number of spines / dendrite length. 
In vitro modulation of $\mathrm{T}_{3}$ in glutamatergic neurons (study III) An in vitro model of cerebral ischemia and electrophysiology studies were performed to study immediate effects of $\mathrm{T}_{3}$ in homeostatic plastic mechanisms, namely modulation of synaptic proteins crucial for neurotransmission and NMDA and AMPA evoked currents.

\section{Cell cultures}

Cultured cortical neurons were used after 7-8 days in vitro (DIV). Primary cortical neuronal cultures were prepared as described before [59]. Cells were obtained from the cerebral cortex from Wistar rats on embryonic day 16-18. Briefly, meninges were removed, and the cortex dissected and subjected to enzymatic dissociation, using 0.05 / 0.02\% $\mathrm{w} / \mathrm{v}$ in phosphate buffered saline (PBS) trypsin / EDTA (\#15400054, Thermofisher) for $15 \mathrm{~min}$ at $37^{\circ} \mathrm{C}$. The homogenized was rinsed with Dulbecco's Modified Eagle's medium (\#11880036, DMEM, GIBCO) with 10\% fetal bovine serum (\#10500-064, GIBCO), $100 \mathrm{U}$ penicillin and streptomycin/ml (\#15140122, Thermofisher), $2 \mathrm{mML-}$ glutamine (\#G5792, Sigma-Aldrich), dissociated with a Pasteur pipette, centrifuged and redissociated in starter medium (\#21103049, Neurobasal medium, GIBCO) supplemented with B27 (\#17504044, GIBCO), $100 \mathrm{U}$ penicillin and streptomycin/ml, $2 \mathrm{mM} \mathrm{L-glutamine} \mathrm{( \# G5792,} \mathrm{Sigma-}$ Aldrich) and $25 \mu \mathrm{M}$ glutamate (\#49621, Sigma-Aldrich). The cells were plated onto poly-L-lysine (\#P4707, SigmaAldrich) pre-coated multiwells at $1.5 \times 10^{5} \mathrm{cells} / \mathrm{cm}^{2}$ and grown in starter medium at $37{ }^{\circ} \mathrm{C}$ and $5 \% \mathrm{CO}_{2}$. One-half of the medium was replaced with cultivating medium (starter medium without glutamate) from 4 DIV. Cells were used after 7-8 DIV for in vitro assays.

\section{In vitro ischemic model and experimental treatments}

After 7 DIV neurobasal medium was collected and stored to be replaced after the experiments. Neuron cultures were washed with PBS, and oxygen and glucose deprivation (OGD) was induced with a deoxygenated aglycemic solution. OGD was generated in a hypoxia incubator chamber (StemCell Technologies), flushed with gas: $5 \% \mathrm{CO}_{2}, 95 \% \mathrm{~N}_{2}$. In control cultures, medium was replaced by basic salt solution (BSS) after washing with PBS and cells were incubated in a normoxic atmosphere containing $5 \% \mathrm{CO}_{2}$. Cultures were in OGD or BSS solutions for $120 \mathrm{~min}$ and after replaced by the previous collected medium. After OGD / BSS conditions, cells were incubated with Vh (DMSO in PBS, 0.01\%) or $\mathrm{T}_{3} 1 \mu \mathrm{M}$ for $48 \mathrm{~h}$. Subsequently, cells were washed with cold PBS to remove excess of culture medium and cells collected and frozen at $-80^{\circ} \mathrm{C}$ until protein extraction.

\section{Immunocytochemistry}

For immunocytochemistry, neurons were plated on glass coverslips and fixed after 7 DIV. Antibodies used for immunofluorescence were rabbit TR $\alpha 1$ (Thermoscientific, 1:500) or rabbit TR $\beta 1$ (Millipore, 1.500). The next day, neurons were stained with Hoechst-33,342 $(4 \mu \mathrm{g} / \mathrm{ml}$, Life Technologies).

\section{Immunobloting}

Protein extraction was performed as previously described $[38,63]$. Western blot was performed to evaluate levels of mouse synaptotagmin (BD Transduction Laboratories, 1:2000).

\section{Electrophysiological recording of membrane currents}

To study ligand-gated channels AMPA and NMDA, we adopted the voltage-ramp method [85].

Individual currents were recorded after incubation with $\mathrm{T}_{3} 1 \mu \mathrm{M}(n=4)$ or $\mathrm{Vh}(n=3)$ during the $48 \mathrm{~h}$ preceding the experiments. A sequence of voltage ramps at a rate of $0.23 \mathrm{mV} / \mathrm{millisecond} \mathrm{were} \mathrm{applied} \mathrm{at} \mathrm{a} \mathrm{holding}$ potential of $-80 \mathrm{mV}$. To obtain the agonist induced current-voltage (I-V) relation, ramps $\mathrm{I}-\mathrm{V}$ curves were constructed applying a 500 milliseconds voltage ramp ranging from $-110 \mathrm{mV}$ to $+20 \mathrm{mV}$ elicited every $8 \mathrm{~s}$. Voltage ramps were applied in the absence and in the presence of AMPA and NMDA agonist glutamate at $50 \mu \mathrm{M}$ and co-agonist of NMDA channels glycine at $3 \mu \mathrm{M}$, to enable subtraction of leak currents. The antagonists of AMPA and NMDA channels, 6-cyano-7-nitroquinoxaline-2,3-dione (CNQX; Sigma-Aldrich) and dizocilpinehydrogen maleate (MK-801; Sigma-Aldrich), respectively, were used both at $10 \mu \mathrm{M}$.

Cell currents were recorded sequentially in the presence of specific $\mathrm{K}^{+}$- channel blockers tetraethylammonium sodium salt $(5 \mathrm{mM})$ and 4-Aminopyridine $(1 \mathrm{mM})$, that were applied in the perfusion system together with the other drugs. Voltage-gated $\mathrm{K}^{+}$channels needed to be blocked, since those channels were contributing to the conductance as well to the reversal potential obtained.

\section{Statistical analysis}

Data are expressed as means \pm standard error of the mean (SEM) for parametric data or as medians for nonparametric data. $P$ values $<0.05$ were considered as statistically significant. Statistical analysis was performed using IBM SPSS statistics 24 software for dendritic spine analysis or GraphPad Prism 6.0 software (GraphPad, San Diego, CA, USA), using one-way analysis of variance (ANOVA) followed by Bonferroni's multiple comparison test when three or more groups were present or twotailed unpaired Student's $t$-test when comparing two groups. For non-parametric data, Kruskal Wallis test was employed for more than two groups followed by the Dunn's multiple comparisons test and the MannWhitney $U$-test for comparison of two groups. Graphs were designed using GraphPad Prism 6.0 software. 
For additional details about techniques and analysis performed, please refer to the Additional file 1: Supplementary Methods.

\section{Results}

Treatment with $\mathrm{T}_{3}$ improves functional recovery after PT without affecting infarct size

We first assessed if treatment with $\mathrm{T}_{3}$ or $\mathrm{T}_{4}$ at 5 or $50 \mu \mathrm{g} / \mathrm{kg}$ enhances motor function in mice subjected to unilateral PT. Motor function was assessed by RPT on day 7 and 14 after stroke onset. We observed some degree of spontaneous recovery in mice of all groups subjected to PT. $\mathrm{T}_{3}$-treated mice at $50 \mu \mathrm{g} / \mathrm{kg}$ could traverse the pole with a score higher than three at $10 \mathrm{rpm}$, to the right and left sides, showing that all animals crossed the pole without falling (Additional file 2: Video S1, Additional file 3: Video S2, Additional file 4: Video S3 and Additional file 5: Video S4). However, a significantly enhanced functional recovery was only observed when the pole rotated at $10 \mathrm{rpm}$ to the left, in animals treated with $\mathrm{T}_{3}$ at $50 \mu \mathrm{g} / \mathrm{kg}$, when compared to Vh-treated animals (Fig. 2a). Fourteen days after stroke, 73\% (eight out of 11 ) and $64 \%$ (seven out of 11) of mice treated with $\mathrm{T}_{3} 50 \mu \mathrm{g} / \mathrm{kg}$ had a score higher or equal to four points, at $3 \mathrm{rpm}$ and $10 \mathrm{rpm}$ to the left, respectively. In contrast, only $9 \%$ (one out of 11) of mice subjected to PT and treated with saline had a score of four points and not higher, at 3 and $10 \mathrm{rpm}$ to the left (Additional file 1: Figure S1).

Infarct size influences the severity of neurological deficits and differences of infarct size among treatment groups may influence behavior assessment to evaluate motor recovery over time. Overall the infarct volume did not differ between animals assigned to treatment groups $\left(2.5 \pm 0.78 \mathrm{~mm}^{3} \mathrm{Vh}, 3.2 \pm 0.97 \mathrm{~mm}^{3} \mathrm{~T}_{3} 5 \mu \mathrm{g} / \mathrm{kg}, 1.6 \pm\right.$ $0.47 \mathrm{~mm}^{3} \mathrm{~T}_{3} 50 \mu \mathrm{g} / \mathrm{kg}, 3.1 \pm 1.5 \mathrm{~mm}^{3} \mathrm{~T}_{4} 5 \mu \mathrm{g} / \mathrm{kg}, 4.0 \pm$ $1.3 \mathrm{~mm}^{3} \mathrm{~T}_{4} 50 \mu \mathrm{g} / \mathrm{kg}$; mean \pm SEM) as shown in Fig. $2 \mathrm{~b}$. All treatments had no influence on the behavior of sham-operated mice (data not shown).

The doses used in the present studies have been determined in preliminary studies (data not shown). No adverse effects related to hyperthyroidism were seen following any of the given doses. In addition, no differences were observed in body weight or temperature in animals from all groups throughout the studies (Additional file 1: Table S1). In all experimental groups, plasma levels of $T_{3}$ and $T_{4}$ were in physiological range at the endpoint of the study (Additional file 1: Figure S2).

We performed the open field test to ascertain that $\mathrm{TH}$ administration was not associated with anxiety or depression-like behavior. Treatment with $\mathrm{TH}$ did not affect open field scores, indicative that the treatment did not induce anxiety (Additional file 1: Figure S3).

\section{Treatment with $\mathrm{T}_{3}$ did not affect the expression of $\mathrm{TH}$ receptors after $\mathrm{PT}$}

To characterize if functional improvement after $\mathrm{T}_{3}$ administration was mediated by its binding to respective TR, we assessed their expression in the post-ischemic brain. We found that both isoforms, TR $\alpha 1$ and TR $\beta 1$, were ubiquitously expressed in the brain. TR were expressed in the cytoplasm of NeuN and $\mathrm{PV}^{+}$neurons in the peri-infarct region and in GFAP positive reactive astrocytes in the glial scar surrounding the infarct (Fig. 2c). In contrast, CD68 positive monocytic phagocytes and GST-pi positive oligodendrocytes were not immunoreactive for TR (Additional file 1: Figure S4).

Importantly, treatment with $\mathrm{T}_{3}$ or $\mathrm{T}_{4}$ at 5 or $50 \mu \mathrm{g} / \mathrm{kg}$ did not change the levels of TR 1 (Fig. 2d), despite there was a nonsignificant elevation of TR $\alpha 1$ protein levels found in protein extracts obtained from the peri-infarct area $\left(0.67 \pm 0.22 \mathrm{Vh}, 0.15 \pm 0.05 \mathrm{~T}_{3}, 1.15 \pm 0.12 \mathrm{~T}_{4}\right.$; arbitrary units, mean \pm SEM). Likewise, no changes have been found in TR $\beta 1$ levels $(1.59 \pm 0.51 \mathrm{Vh}, 1.61 \pm 0.20$ $\mathrm{T}_{3}, 1.74 \pm 0.42 \mathrm{~T}_{4}$; arbitrary units, mean \pm SEM) (Fig. 2e).

\section{Thyroid hormone receptor pattern expression in human stroke patients}

Both receptor isoforms were also found in post-mortem brain tissues. The levels for both isoforms did not differ between the peri-infarct area from stroke patients and cortex samples from non-stroke patients. However, differences were observed in the infarct core. Here, TR $\beta 1$ protein levels increased $(0.37 \pm 0.02 \mathrm{Ctrl}, 0.32 \pm 0.03 \mathrm{PI}$, $0.63 \pm 0.07 \mathrm{IC}$; arbitrary units, mean \pm SEM) while levels of TR $\alpha 1$ decreased $(0.85 \pm 0.13$ Ctrl, $0.91 \pm 0.16 \mathrm{PI}$, $0.38 \pm 0.15 \mathrm{IC}$; arbitrary units, mean \pm SEM) (Fig. $2 \mathrm{f}, \mathrm{g}$ ).

\section{Treatment with $T_{3}$ increases dendritic spine density in principal neurons and modulates synaptic neurotransmission}

Using Thy1-YFP transgenic mice, we performed a second study to evaluate if $\mathrm{T}_{3}$ at $50 \mu \mathrm{g} / \mathrm{kg}$ was involved in modulation of dendritic spine density and morphology as an estimate of structural plasticity in the postischemic brain. The study design including surgeries and treatment with $\mathrm{T}_{3}$ at $50 \mu \mathrm{g} / \mathrm{kg}$ or $\mathrm{Vh}$ were adopted from Study I. To determine the possibility of formation of new synaptic connections 14 days after $\mathrm{T}_{3}$ administration, we evaluated dendritic spine density and morphologic classification in four regions corresponding to the peri-infarct area and remote areas to stroke (Fig. 3a).

Infarct volumes did not differ between the treatments $\left(1.0 \pm 0.45 \mathrm{~mm}^{3} \mathrm{Vh}, 1.32 \pm 0.41 \mathrm{~mm}^{3} \mathrm{~T}_{3} ;\right.$ mean $\left.\pm \mathrm{SEM}\right)$ and did not affect dendritic spines in regions of interest. Representative dendritic branches from mice treated either with $\mathrm{T}_{3}$ at $50 \mu \mathrm{g} / \mathrm{kg}$ or $\mathrm{Vh}$ are shown in Fig. 3b. 

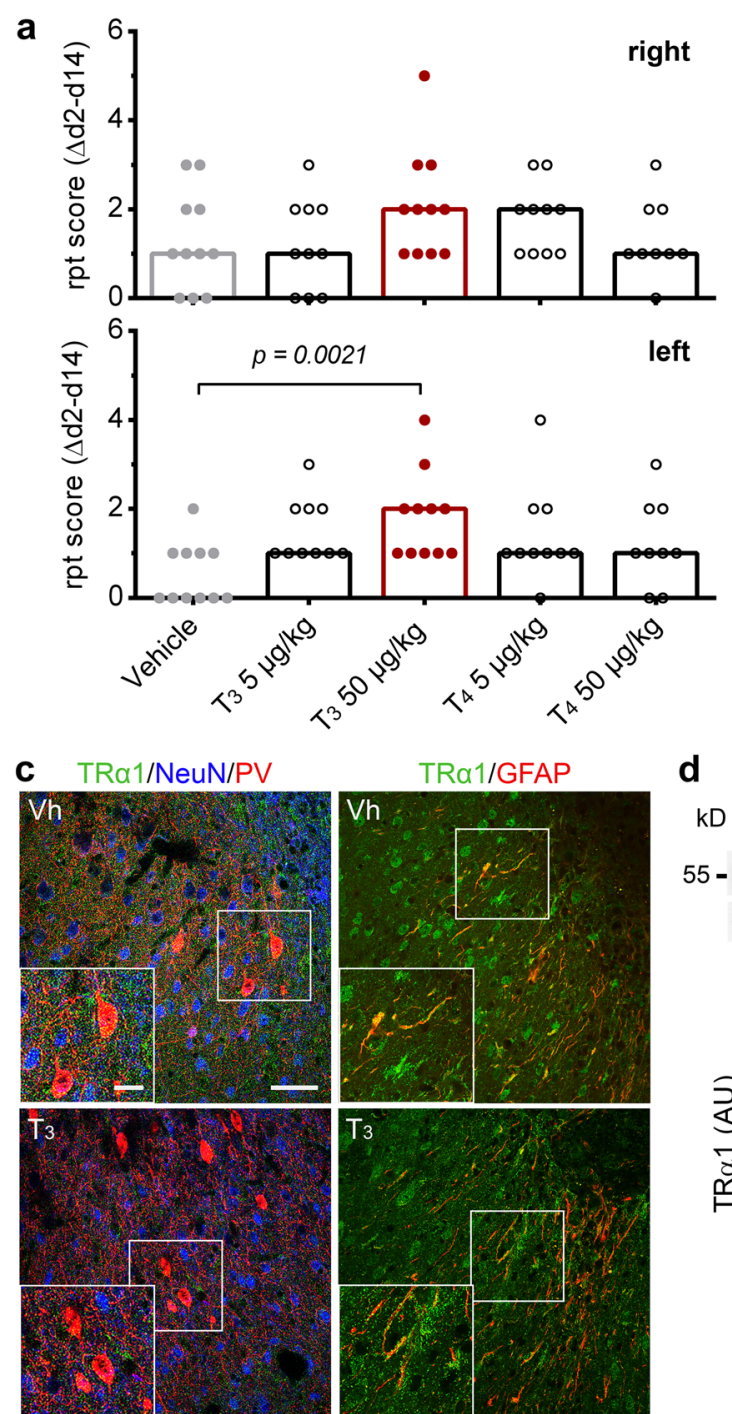

TRß1/NeuN/PV
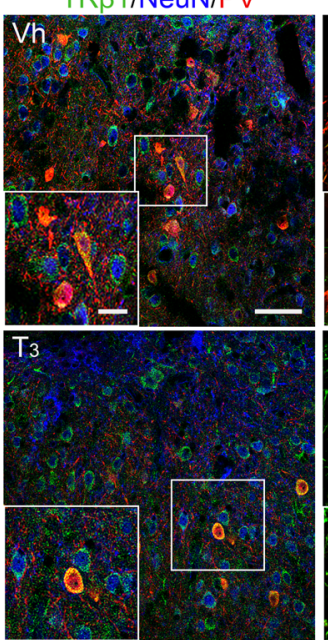

Fig. 2 (See legend on next page.)

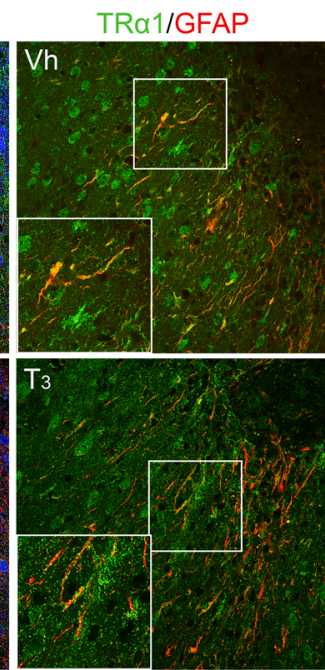

TRB1/GFAP

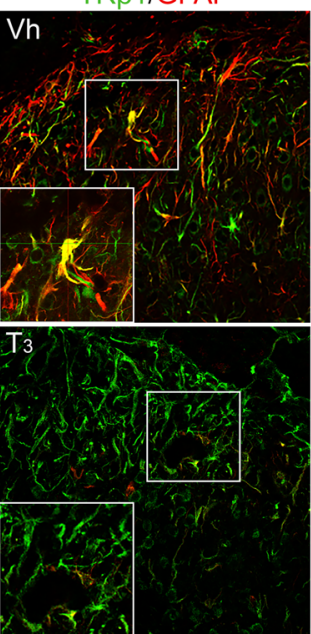

e b
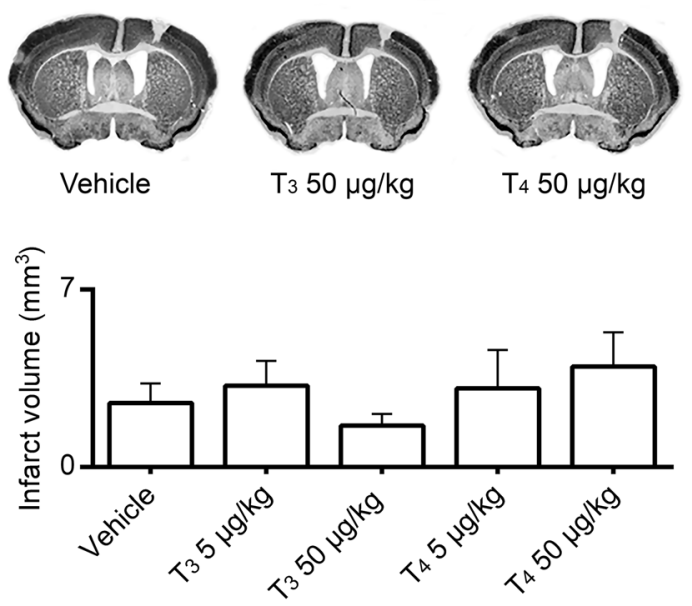

f
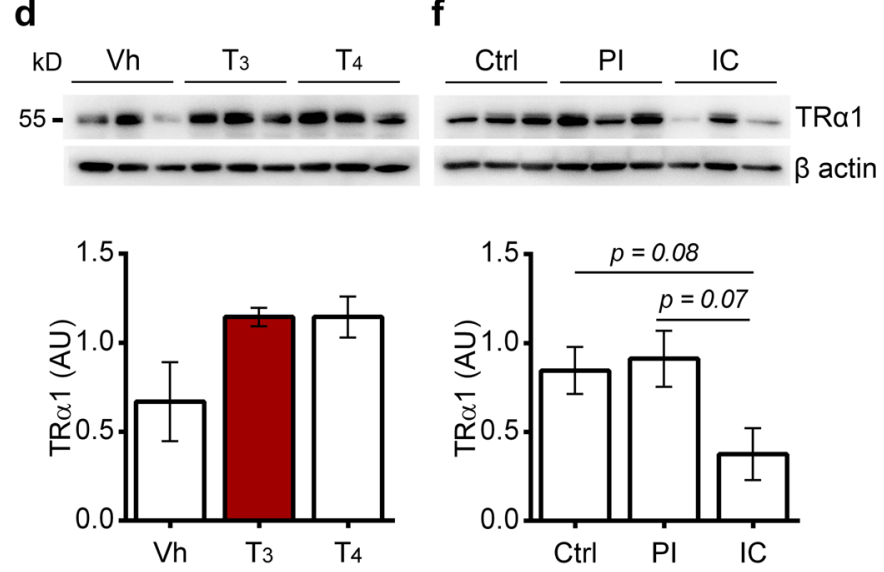

g
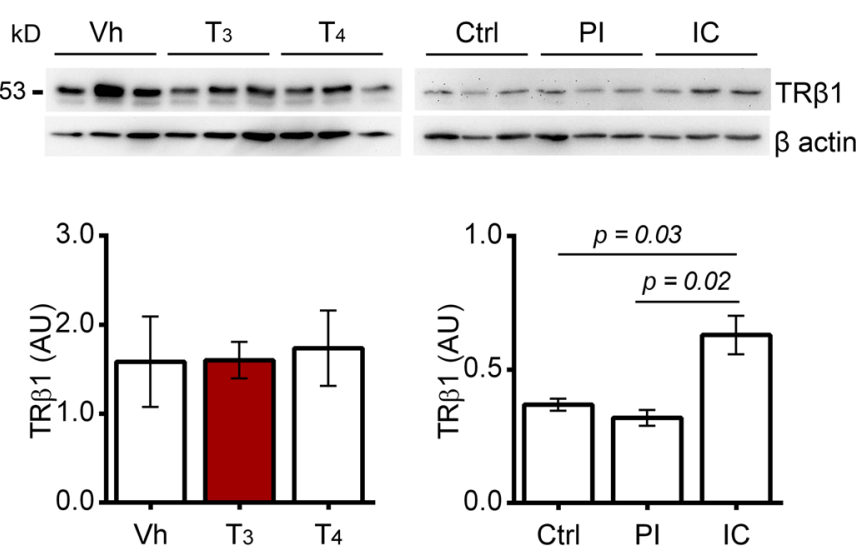
(See figure on previous page.)

Fig. 2 Treatment with $T_{3} 50 \mu \mathrm{g} / \mathrm{kg}$ improves functional recovery 14 days after photothrombosis (PT) without affecting infarct size. a Difference between the rotating pole test (rpt) scores from day 2 (selective sorting) and 14 ( $\Delta \mathrm{d} 2$-d14) at 10 rotations per minute to the right and to the left sides, from mice subjected to PT (right hemisphere). Scores are shown as individual data and group median. Statistical analysis was performed by Kruskal-Wallis test followed by Mann-Whitney test ( $p=0.0021$ in $T_{3} 50 \mu \mathrm{g} / \mathrm{kg}$ versus Vehicle treatment). Vehicle $(n=11), T_{3} 5 \mu \mathrm{g} / \mathrm{kg}(n=10), T_{3} 50$ $\mu \mathrm{g} / \mathrm{kg}(n=11), \mathrm{T}_{4} 5 \mu \mathrm{g} / \mathrm{kg}(n=10), \mathrm{T}_{4} 50 \mu \mathrm{g} / \mathrm{kg}(n=9) . \mathbf{b}$ Representative coronal brain sections from stroke mice treated with Vehicle, $\mathrm{T}_{3} 50 \mu \mathrm{g} /$ $\mathrm{kg}$ or $\mathrm{T}_{4} 50 \mathrm{\mu g} / \mathrm{kg}$. Staining with NeuN was performed to measure cortical infarcts. Infarct volumes are displayed as means \pm SEM. On day 14 after PT in mice treated with Vehicle $(n=10), T_{3} 5 \mu \mathrm{g} / \mathrm{kg}(n=8), \mathrm{T}_{3} 50 \mu \mathrm{g} / \mathrm{kg}(n=8), \mathrm{T}_{4} 5 \mu \mathrm{g} / \mathrm{kg}(n=7)$ or T $40 \mu \mathrm{g} / \mathrm{kg}(n=7)$. Statistical analysis was performed by one-way ANOVA and Bonferroni's multiple comparisons test. c Thyroid hormone receptors (TR) a1 and TR 31 (AF488, green) expression in mouse brain cell populations. Both TR isoforms are expressed in NeuN (Cy5, blue) positive neurons and Parvalbumin (Cy3, red) positive neurons. GFAP (Cy3, red) immunoreactive astrocytes express TR $\beta 1$ in the ischemic territory, 14 days after PT. Scale bars $50 \mu m$ and $10 \mu m$ for insets at higher magnification. $\mathbf{d}$ Levels of TRa1 and e TR $\beta 1$ in the infarct core and peri-infarct area were analyzed 14 days after PT and after treatment with Vehicle $(n=3), T_{3} 50 \mu \mathrm{g} / \mathrm{kg}(n=3)$ or $\mathrm{T}_{4} 50 \mu \mathrm{g} / \mathrm{kg}(n=3)$. No difference was observed in levels of TRa1 and TR 1 . f Levels of TRa1 and $\mathbf{g}$ TR $\beta 1$ in the grey matter of human brain in non-stroke (Ctrl), and stroke cases, including the peri-infarct (PI) and infarct core (IC). For uncropped images of western blots see Additional file 1: Figure S5. Levels of TRß1 are increased in the IC. Statistical analysis was performed by One-way ANOVA and Bonferroni's multiple comparisons test. Two-tailed unpaired Student's $t$ test was employed to determine $p$ values. Data are expressed as mean \pm SEM

Each dendritic spine was classified as mushroom, thin or stubby using the NeuronStudio software (Fig. 3c).

Throughout all three levels covering the anterior, middle and posterior peri-infarct area and homotypic regions of the contralateral hemisphere, the overall number of dendritic spines was increased in $\mathrm{T}_{3}$-treated animals compared to Vh-treated animals. In particular, a significant increase in mushroom type spines was observed in R1, level 1, thin spines in R3 and R4 from level 1 and R1 and R2 from level 2 and stubby spines in R2 and $\mathrm{R} 4$ of levels 2 and 3 ( $p<0.001$, all regions). Together, we found an increment of dendritic spine density in $\mathrm{T}_{3}$-treated animals, in all regions and sections analyzed, particularly in the region correspondent of ipsilateral somatosensory cortex (Fig. 3d).

These findings prompted us to investigate if treatment with $\mathrm{T}_{3}$ at $50 \mu \mathrm{g} / \mathrm{kg}$ modulates pre- and/or postsynaptic proteins, which reflects structural changes in dendritic spines and the number of functional synapses relevant for synaptic neurotransmission in the peri-infarct area. We observed no differences in the level of the presynaptic synaptophysin and the PSD95 (Fig. 4). Likewise, no differences were detected in NMDAR1. Interestingly, we found that glutamate receptor 2 (GluR2), one of the AMPA receptor subunits, was significantly increased in mice subjected to PT and treated with $\mathrm{T}_{3}$ while levels of GluR1 remained stable (Fig. 4). Accompanied we found increased levels of synaptotagmin $1 \& 2$. In sham operated control experiments, treatment with $\mathrm{T}_{3}$ had no effect on all studied proteins.

\section{Synaptotagmins are downregulated by $T_{3}$ in an in vitro model of ischemia and are downregulated in the infarct core of human stroke}

The finding that $\mathrm{T}_{3}$ at $50 \mu \mathrm{g} / \mathrm{kg}$ modulates levels of synaptotagmin $1 \& 2$ in vivo prompted us to evaluate its expression in OGD-treated neuronal cultures pre-treated with $\mathrm{T}_{3} 1 \mu \mathrm{M}$ for $48 \mathrm{~h}$. Levels of synaptotagmin were significantly decreased in neuronal cultures in the presence of $\mathrm{T}_{3}$ (Fig. 5a). This pre-synaptic protein was also expressed in the ischemic territory of stroke patients, being significantly reduced in the infarct core (Fig. 5b).

\section{$\mathrm{T}_{3}$ inhibits glutamate evoked currents in glutamatergic cortical neurons}

To study the relevance of $\mathrm{T}_{3}$ for neuron function we used the method of voltage ramp to establish information about the I-V relations of calcium permeable NMDA and AMPA post-synaptic receptors in the presence and absence of $T_{3}$. For each cell tested, membrane current amplitudes were normalized in order to obtain current density (pA/pF).

Glutamatergic neurons responsiveness to $\mathrm{T}_{3}$ stimulation was consistent with the positive immunoreactivity for TR $\alpha 1$ and TR $\beta 1$ (Fig. 5c). Application of agonist glutamate at $50 \mu \mathrm{M}$ and NMDA co-agonist glycine at $3 \mu \mathrm{M}$ elicited an inward component at negative potentials. Glycine together with glutamate potentiated the glutamate induced current, even in the presence of $\mathrm{Mg}^{2+}$ in the extracellular bath. We also examined the possibility of glycine to induce currents by itself. Application of glycine at $3 \mu \mathrm{M}$ did not induce a current in any of the neurons tested (Additional file 1: Figure S8). We also tested if response was mediated by postsynaptic iGluRs NMDA and AMPA, by application of non-competitive antagonists MK-801 and CNQX at $10 \mu \mathrm{M}$, respectively. After application, currents were almost reversed (Fig. 5d). Similarly, to the application of the antagonists, currents are also almost reversed after washout with extracellular bath (data not shown).

Compared with cells in control conditions, the presence of $\mathrm{T}_{3}(1 \mu \mathrm{M})$ in cell cultures for $48 \mathrm{~h}$ before the experiments significantly decreased glutamate / glycine response in the neurons analyzed (Fig. 5e).

\section{$\mathrm{T}_{3}$ downregulates GABA synthesis and activity of cortical Parvalbumin immunoreactive cells}

To determine whether functional recovery mediated by i.p. injection of $\mathrm{T}_{3}$ at $50 \mu \mathrm{g} / \mathrm{kg}$ modulates GABAergic 
a

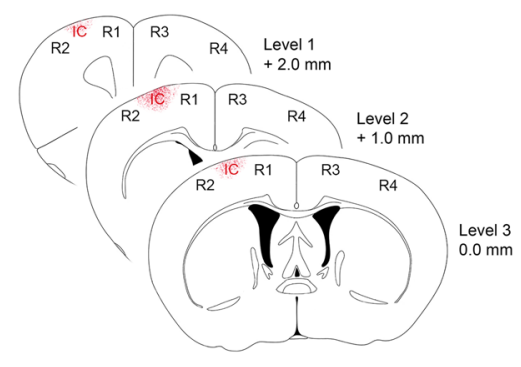

b

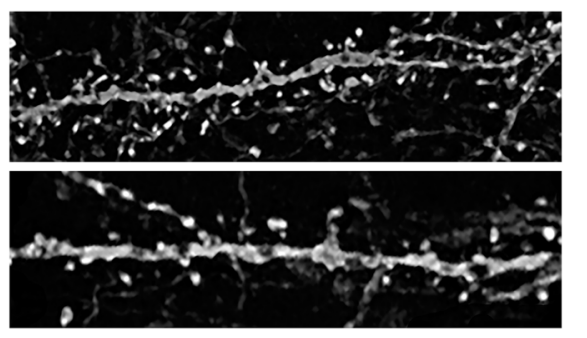

T3 $50 \mu \mathrm{g} / \mathrm{kg}$

Vehicle

C

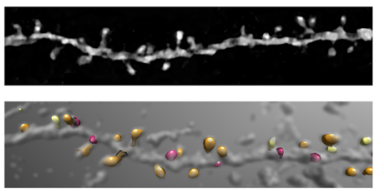

Mushroom Thin Stubby

d

Level 1

Level 2

Level 3
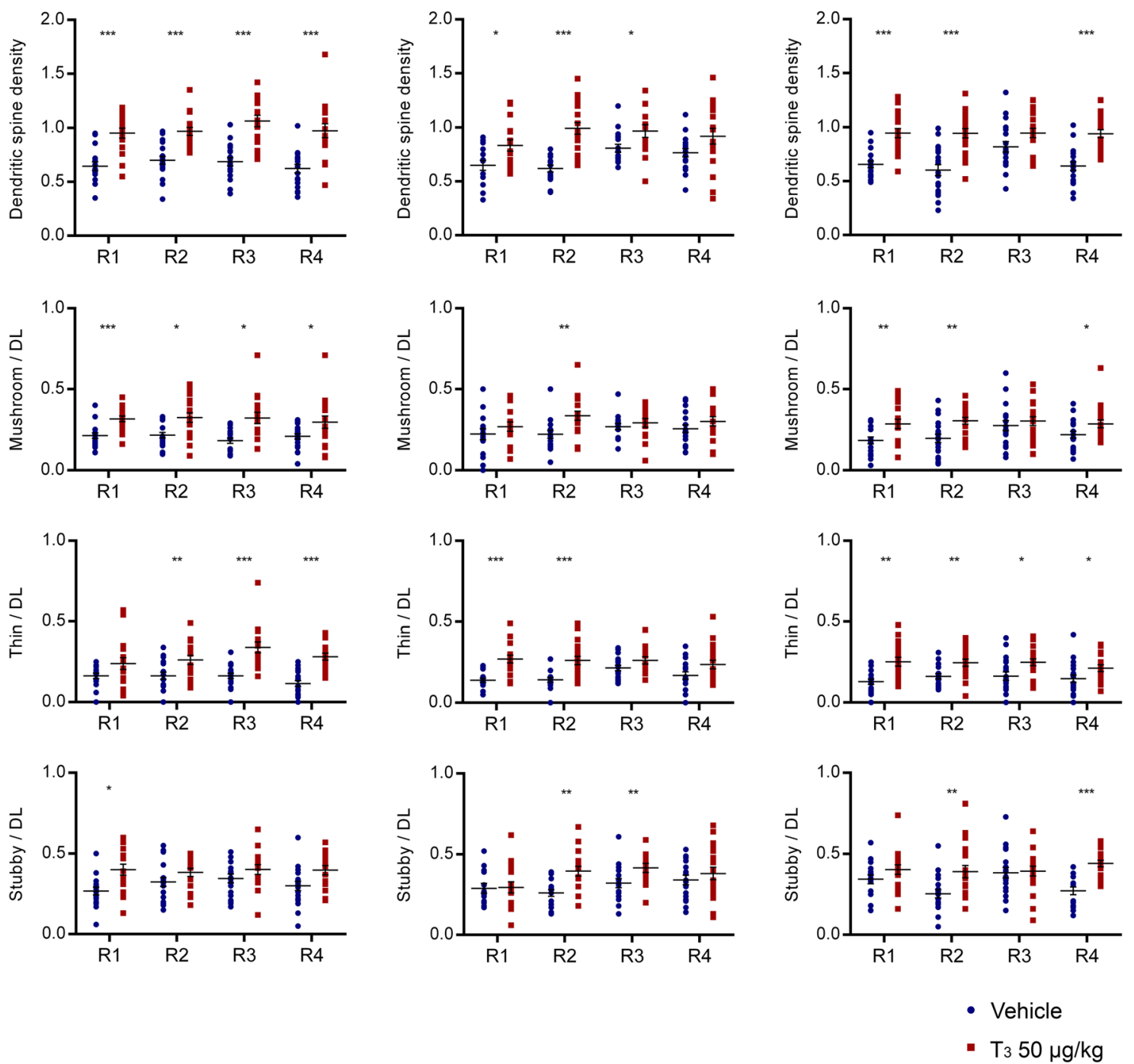

Fig. 3 (See legend on next page.) 
(See figure on previous page.)

Fig. 3 Treatment with $T_{3} 50 \mu \mathrm{g} / \mathrm{kg}$ increases dendritic spine density 14 days after photothrombosis (PT). a Dendritic spine analysis 14 days after PT at different distances from bregma correspondent to the rostral pole (level 1), center (level 2) and caudal pole (level 3) of the cortical infarct. The regions analyzed correspond to the ipsilateral (R1) and contralateral (R3) motor cortex; and ipsilateral (R2) and contralateral (R4) somatosensory cortex. $\mathbf{b}$ Representative dendritic segments from animals treated with $\mathrm{T}_{3} 50 \mathrm{\mu g} / \mathrm{kg}(n=4)$ and Vehicle $(\mathrm{Vh} ; n=4)$. c Apical dendritic spines from cortex layers II/III were automatically detected by NeuronStudio software and classified as mushroom, thin or stubby. Three to five dendritic segments were analyzed per animal. d Dendritic spine density (number of total spines / dendritic length) per region and classification of dendritic spines as mushroom, thin or stubby and their density per region, at each level analyzed. Results are displayed as means \pm SEM. Statistical analysis was performed with two-tailed unpaired Student $t$-test, ${ }^{*} p<0.05,{ }^{* *} p<0.01,{ }^{* *} p<0.001$

signaling, we evaluated GAD 65/67 expression in stroke mice treated with $\mathrm{T}_{3}$ compared with Vh. Longterm administration of $\mathrm{T}_{3} 50 \mu \mathrm{g} / \mathrm{kg}$ for 14 days after ischemic stroke significantly reduced GAD 65/67 expression in the ischemic territory. In sham operated animals, administration of $\mathrm{T}_{3}$ did not alter the expression of GAD 65/ 67 (Fig. 6a).
To understand the significance of lower GAD 65/67 expression in animals treated with $\mathrm{T}_{3}$, we assessed the activity of cortical PV neurons, a class of interneurons that regulate GABA neurotransmission. PV immunoreactivity was co-localized with the activity-dependent marker c-fos, through NovaRED Peroxidase (PV) and DAB (c-fos) immunohistochemistry (Fig. 6b, c). As
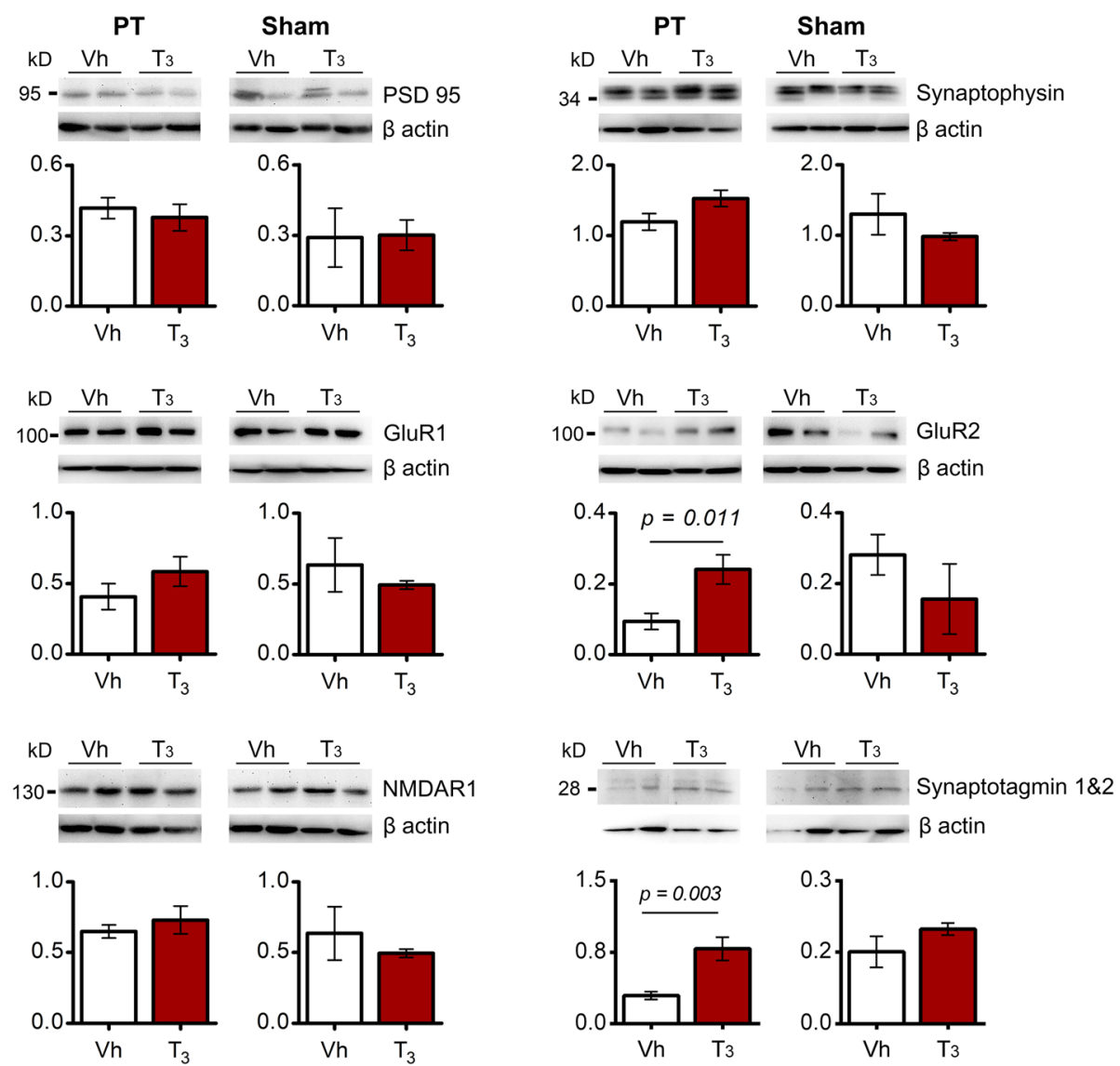

Fig. 4 Levels of synaptic proteins in the infarct core and peri-infarct area 14 days after photothrombosis (PT) or in the homotypic area in sham operated mice have been analyzed after treatment with Vehicle (Vh; $n=6$ for PT and $n=3$ for sham) or T $50 \mu \mathrm{g} / \mathrm{kg}$ ( $n=6$ for PT and $n=3$ for sham). There are no significant differences between levels of postsynaptic density protein 95 (PSD95), synaptophysin, glutamate receptor 1 (GluR1) and NMDA receptor 1 in the infarct core and peri-infarct in $T_{3}$-treated mice compared with Vh. Levels of AMPA receptor subunit GluR2 and synaptotagmin $1 \& 2$ are increased in the infarct core and peri-infarct in $T_{3}$-treated mice compared with Vh. Synaptotagmins are vesicleassociated synaptic proteins involved in neurotransmitter release. For uncropped images of western blots see Additional file 1: Figure S6. No differences were observed in sham operated mice. Results are displayed as means \pm SEM. Statistical analysis was performed with two-tailed unpaired Student's $t$ test 

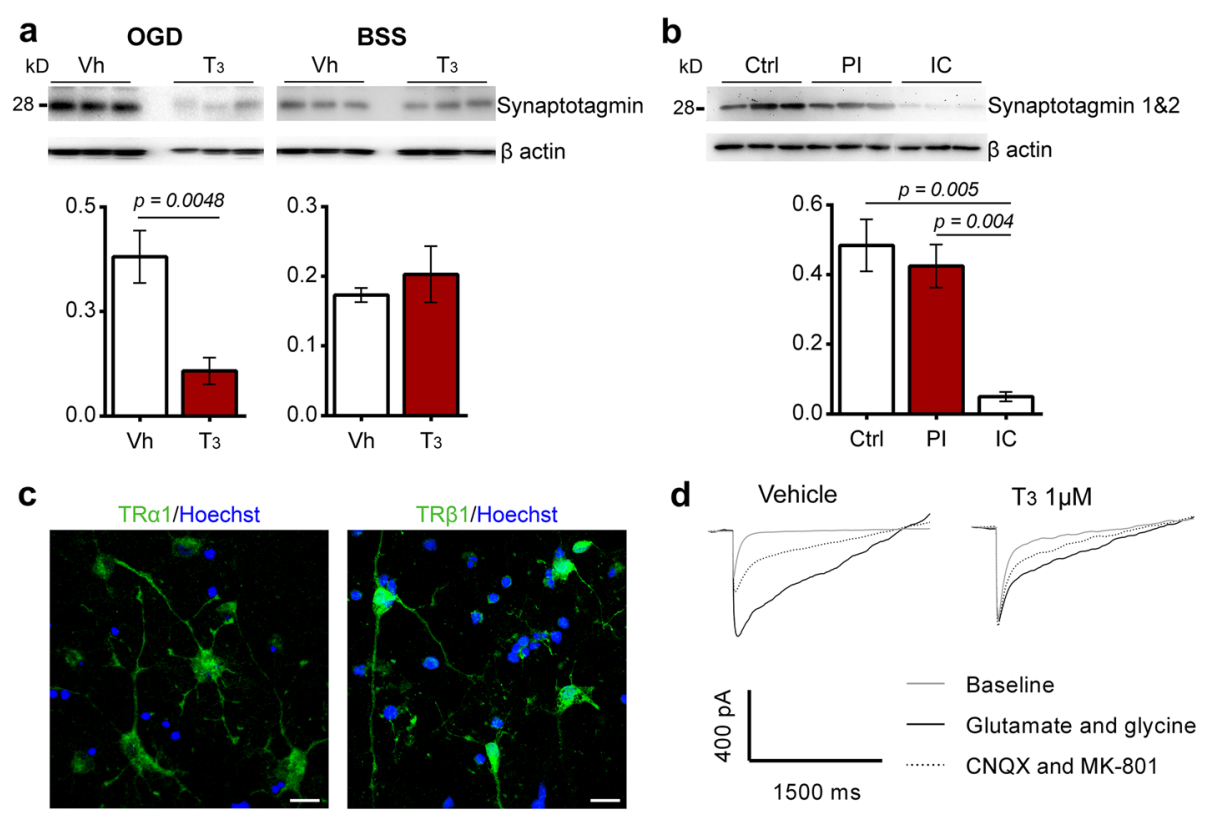

e

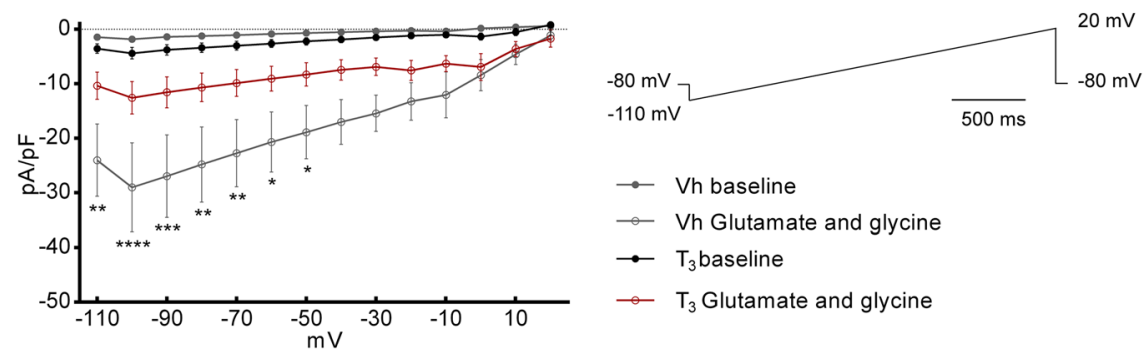

Fig. 5 Treatment with $T_{3} 1 \mu \mathrm{M}$ for $48 \mathrm{~h}$ inhibits iGluRs evoked currents in cultured cortical glutamatergic neurons and downregulates synaptotagmin levels after oxygen and glucose deprivation (OGD). a In an in vitro model of acute cerebral ischemia, levels of synaptotagmin are decreased in cells pre-treated with $\mathrm{T}_{3} 1 \mu \mathrm{M}$ for $48 \mathrm{~h}$ but no difference was observed in the control conditions $\left(\mathrm{Vh}, n=5 ; \mathrm{T}_{3} 1 \mu \mathrm{M}, n=5\right)$. $\mathbf{b}$ Human brains of stroke and non-stroke control cases have been analyzed for levels of synaptotagmin 1\&2. Levels of synaptotagmin are decreased in the infarct core (IC) in comparison with control ( $\mathrm{Ctrl}$ ) and peri-infarct (PI) regions ( $n=3$ for each brain region). For uncropped images of western blots see Additional file 1 : Figure S7 c Representative images of expression of Thyroid hormone receptors TRa1 and TRß1 (AF488, green) in cultured cortical glutamatergic neurons. TRa 1 was mainly localized in the cytoplasm and TRß1 was expressed in the cytoplasm and nucleus. Scale bar $20 \mu m$. $\mathbf{d}$ Representative traces obtained during voltage ramps from -110 to $+20 \mathrm{mV}$ after application of glutamate $50 \mu \mathrm{M}$ and glycine $3 \mu \mathrm{M}$, held at $-80 \mathrm{mV}$. After application of AMPA and NMDA antagonists, CNQX and MK-801 respectively, currents were almost fully reverted. e I-V relationship of glutamate $50 \mu \mathrm{M}$ and glycine $3 \mu \mathrm{M}$ induced current in cortical neurons under voltage clamp condition under the membrane potential of $-80 \mathrm{mV}$. Each trace is the result of the average of three ramps for each $10 \mathrm{mV}\left(\mathrm{Vh}, n=3 ; \mathrm{T}_{3} 1 \mu \mathrm{M}, n=4\right)$. Results are displayed as means $\pm \mathrm{SEM}$. Statistical analysis was performed with twotailed unpaired Student's $t$ test to compare glutamate induced currents in cells pre-treated with $\mathrm{T}_{3} 1 \mu \mathrm{M}$ for $48 \mathrm{~h},{ }^{*} p<0.05$, ${ }^{* *} p<0.01,{ }^{* * *} p<0.001$

shown in Fig. 6d, there is a significant reduction in $\mathrm{PV}^{+} /$ $\mathrm{c}^{-\mathrm{fos}^{+}}$ratio between $\mathrm{Vh}$ and $\mathrm{T}_{3} 50 \mu \mathrm{g} / \mathrm{kg}$-treated animals in the peri-infarct region $(40.46 \pm 4.26 \mathrm{Vh} ; 14.62 \pm 3.4$ $\mathrm{T}_{3} 50 \mu \mathrm{g} / \mathrm{kg}$; mean $\left.\pm \mathrm{SEM}\right)$ and the homotypic region in the contralateral hemisphere $(43.61 \pm 9.43 \mathrm{Vh}$, $11.54 \pm 4.12 \mathrm{~T}_{3} 50 \mu \mathrm{g} / \mathrm{kg}$; mean $\left.\pm \mathrm{SEM}\right)$. In contrast, treatment with $\mathrm{T}_{4} 50 \mu \mathrm{g} / \mathrm{kg}$ did not change the activity of $\mathrm{PV}^{+}$cells in the same regions (Ipsilateral 33.97 \pm 7.59 ; Contralateral $35.91 \pm 2.65$; mean \pm SEM). Importantly, treatment with $\mathrm{TH}$ did not influence the total number of PV immunoreactive cells in the ipsilateral and contralateral hemispheres (Fig. 6d).

\section{Discussion}

After an ischemic stroke, there is a disruption of normal neuron function i.e. synaptic activity due to cell death occurring in the infarct core and therefore, disruption in the normal neuronal circuity [87]. As consequence, surviving neurons adjacent to the infarct spontaneously adopt homeostatic mechanisms that contribute to maintain overall excitability, although to a limited extent [18, $21,48]$. The molecular mechanisms of homeostatic processes characterize the recovery phase of ischemic stroke and enhancing those with adjuvant interventions might be a key therapeutic strategy [19]. This may create a 


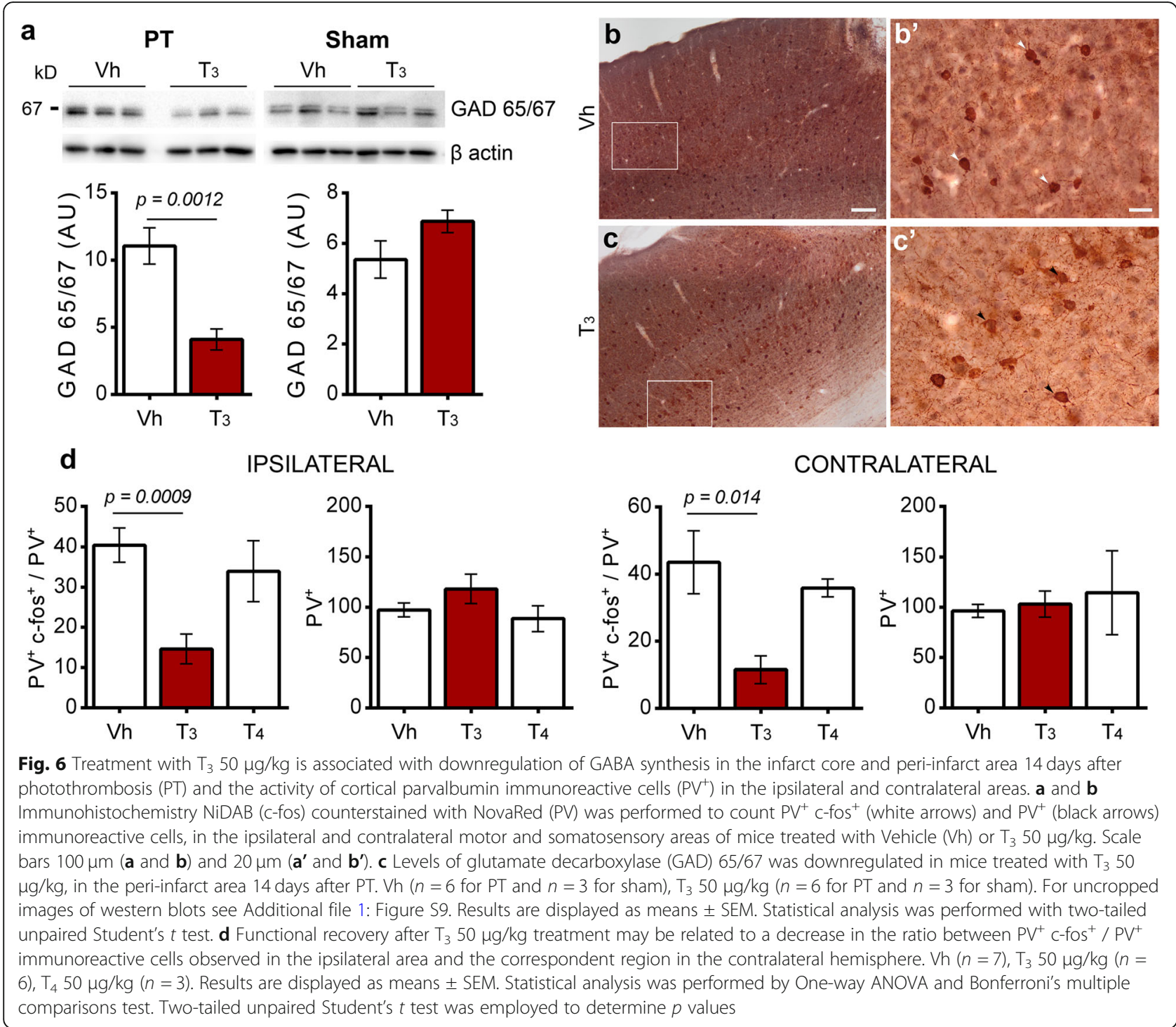

wider therapeutic window to optimize and restore lost neurological function.

$\mathrm{TH}$ have been recently proposed as a key modulator in stroke [71] and brain injury recovery [41]. The lacking evidence of the underlying mechanisms of TH promoting functional recovery after stroke prompted us to evaluate the role of TH in the post-ischemic brain. Summarizing, our work demonstrates for the first time that $\mathrm{T}_{3}$ modulates key homeostatic regulatory mechanisms that are crucial to maintain appropriate levels of excitation and mechanisms that stabilize neuronal activity in the post-ischemic brain, contributing to cortical reorganization and to functional recovery.

Given that TH signaling could be related to better outcome, we first assessed behavioral recovery after experimental stroke in mice treated with $\mathrm{T}_{4}$ or $\mathrm{T}_{3}$ at 5 or $50 \mu \mathrm{g} / \mathrm{kg}$. The photothrombotic model adopted for our study induced a well-defined ischemic damage in the primary motor cortex that produced consistent hemiparesis 2 days after stroke [53], allowing behavioral assessment of motor function following ischemia. As expected, all mice spontaneously recovered some of lost motor function over time in analogy to spontaneous recovery in humans [23, 24]. Interestingly, the group treated with $\mathrm{T}_{3} 50 \mu \mathrm{g} / \mathrm{kg}$ had significant higher neurological scores 14 days after PT, with no difference in the infarct size compared to control group. However no significant statistical differences were observed in the $\mathrm{T}_{4}$-treated mice groups. $\mathrm{T}_{4}$ is the prohormone and it needs to be converted to $\mathrm{T}_{3}$ before it can exert any biological effect [47]. In the rodent, half of $\mathrm{T}_{3}$ levels in the brain is provided from its free fraction in blood circulation and cerebrospinal fluid and the other half relies in local deiodination of $\mathrm{T}_{4}$ in astrocytes and tanycytes, which concentration is 
regulated by deiodinases activity [44, 74]. Although we did not verify deiodinase expression in the post ischemic brain, the possible scenario is that administration of $\mathrm{T}_{4}$ is less effective to exert action in the brain, since it still needs to be converted to the active form $\mathrm{T}_{3}$.

Next, we investigated the key $\mathrm{T}_{3}$-mechanisms that might contribute for stroke recovery. Taking into account that genomic actions of $\mathrm{T}_{3}$ in the brain are mainly mediated by binding to TR $\alpha 1$ and $\operatorname{TR} \beta 1$ [71], we assessed their levels and expression pattern in the postischemic mouse brain. TR levels were not altered after administration of $\mathrm{T}_{4}$ or $\mathrm{T}_{3}$ at $50 \mu \mathrm{g} / \mathrm{kg}$, suggesting that recovery induced by $\mathrm{T}_{3}$ was mediated by other mechanisms. However, our results do not exclude the possibility that genomic actions in the brain have an impact on stroke recovery also at different temporal and spatial scales, in other animal models or in humans. Indeed, one study reported a reduction of TR $\beta 1$ expression in the infarct core compared with unaffected peri-infarct cortex and contralateral hemisphere 14 days after permanent middle cerebral occlusion (MCAO) [43]. We also found that TR $\beta 1$ was significantly increased in the infarct core in the human brain, when compared to nonstroke patients. Taken together, we show that cerebral ischemia induces heterogenic changes in human brain TR expression, which may imply an important role for $\mathrm{T}_{3}$ signaling.

Although TR are mainly nuclear, TR $\alpha 1$ and TR $\beta 1$ have been also found in the cytoplasm, which may increase $\mathrm{T}_{3}$ nuclear import [2]. Interestingly, we observed that TR $\alpha 1$ and TR $\beta 1$ was heterogeneously expressed in the cytoplasm of neurons and in reactive astrocytes from the glial scar, in accordance with a previous study performed 14 days after MCAO [43]. However, none of TR isoforms were found in positive GFAP astrocytes in the naïve rodent brain [14]. If TR expression has implications in the formation and function of the glial scar should be the subject for subsequent studies.

Besides genomic actions, other TH-mediated nongenomic mechanisms may contribute for stroke [71] and brain injury [41] recovery. After ischemic stroke, there is an extensive and rapid loss of neurons and degeneration of their axons and dendritic spines in remote areas [87], in both ipsilateral and contralateral cortex [31], leading to a disruption in normal function of neuronal circuits and loss of brain function. In analogy to brain development and learning/plasticity mechanisms, surviving neurons after stroke attempt to stabilize the ratio between excitatory - inhibitory circuits, in order to adjust brain excitability [21]. A wide variety of homeostatic mechanisms might contribute to the maintenance of overall excitability, involving the regulation of neuronal intrinsic excitability and synaptic transmission [52, 76, 77]. Here, we have identified for the first time $\mathrm{T}_{3}$-modulated mechanisms of homeostatic plasticity that were related to motor recovery after experimental stroke. In particular, we have shown that $T_{3}$ modulates plasticity mechanisms that may operate on different temporal and spatial scales as compensatory mechanisms to assure appropriate synaptic neurotransmission.

Dendritic spines are highly dynamic $[6,84]$ and especially after stroke it occurs an extensive reorganization in dendritic arbors, which includes an increase in spine density and spine turnover [12, 13, 25], particularly in apical cortical pyramidal neurons within the first 2 weeks [11]. In Study II we observed overall enhanced cortical reorganization in $\mathrm{T}_{3}$-treated Thy1-YFP mice reflected in increased spine density in cortical layers II/ III, especially in the peri-infarct area, which may contribute for spontaneous recovery. The process of spine formation or spinogenesis includes the formation of thin and long dendritic filopodia that are highly dynamic and establish contact with presynaptic axons. The presence of appropriate signals would result in stabilization of the contact and maturation of filopodia into functional dendritic spines [6]. Interestingly, we found increased density of thin protrusions in $\mathrm{T}_{3}$-treated animals, especially in the peri-infarct area, although in a temporal scale we could not distinguish newly formed protrusions from the pre-existing ones. We also observed an increased number of mushroom-like spines in the peri-infarct region in all sections analyzed from $\mathrm{T}_{3}$-treated mice. $\mathrm{Al}$ though we could not assure that all protrusions are or will be transformed in more stable thin or mushroomlike spines over time, this was a direct finding that $T_{3}$ modulated the reorganization of spines in numbers and structure 2 weeks after stroke onset.

Based on these findings, we further evaluated synaptic efficacy. To address this question, we studied levels of pre-synaptic proteins synaptophysin and synaptotagmin, important to regulate endocytosis and exocytosis of synaptic vesicles, respectively [39, 68, 69] and therefore neurotransmitter release. In particular, synaptotagmins are crucial for the docking of synaptic vesicles and fusion with neuron membrane [69]. We demonstrate that in the human ischemic infarct core, levels of synaptotagmin $1 \& 2$ were very low due to cell death and loss of synaptic neurotransmission. Nevertheless, their levels in the peri-infarct remained as the same as non-stroke brain tissue, which makes synaptotagmin a molecular target. The increase in synaptotagmin $1 \& 2$ levels in the postischemic brain of $\mathrm{T}_{3}$-treated mice supports an increase of neurotransmitter release probability, which in turn may increase synaptic efficacy [9]. In contrast, we observed that synaptotagmin is reduced in OGD $\mathrm{T}_{3}$-treated cultured glutamatergic neurons, which demonstrated homeostatic regulation by $\mathrm{T}_{3}$ in order to reduce neurotransmitter release and hyperexcitability in an in vitro 
model of acute brain ischemia. Synaptotagmin related gene 1 is a TH responsive gene during brain development, regulating synaptic activity and structure [73] and $\mathrm{T}_{4}$ has been reported to restore synaptotagmin 1 levels to normal in hypothyroid rats [83]. However, how $\mathrm{T}_{3}$ activates / inhibits synaptic vesicles for synaptotagmin action remains to be elucidated.

Besides neurotransmitter release, efficacy of neurotransmission is dependent on post-synaptic response to glutamate in neuron terminals, that can be modulated by changing the number or function of iGluRs AMPA and NMDA [10, 51, 75, 76]. Indeed, stroke-induced glutamate release activates AMPA receptors [17] and NMDA receptors [54], changes that are related with excitatory synaptic transmission and motor recovery. Here we show an increase in levels of AMPA receptor subunit GluR2 in the peri-infarct area of mice treated with $T_{3}$. The AMPA receptor subunit GluR2 regulates critical aspects of AMPA receptor function, neurotransmission and synaptic plasticity $[32,66]$ which ultimately contributes to increased excitability in the post-ischemic brain and recovery [67].

We characterized AMPA and NMDA excitatory postsynaptic currents with a voltage-clamp method in

\section{A. Longterm effects of $\mathrm{T}_{3}$ after stroke}

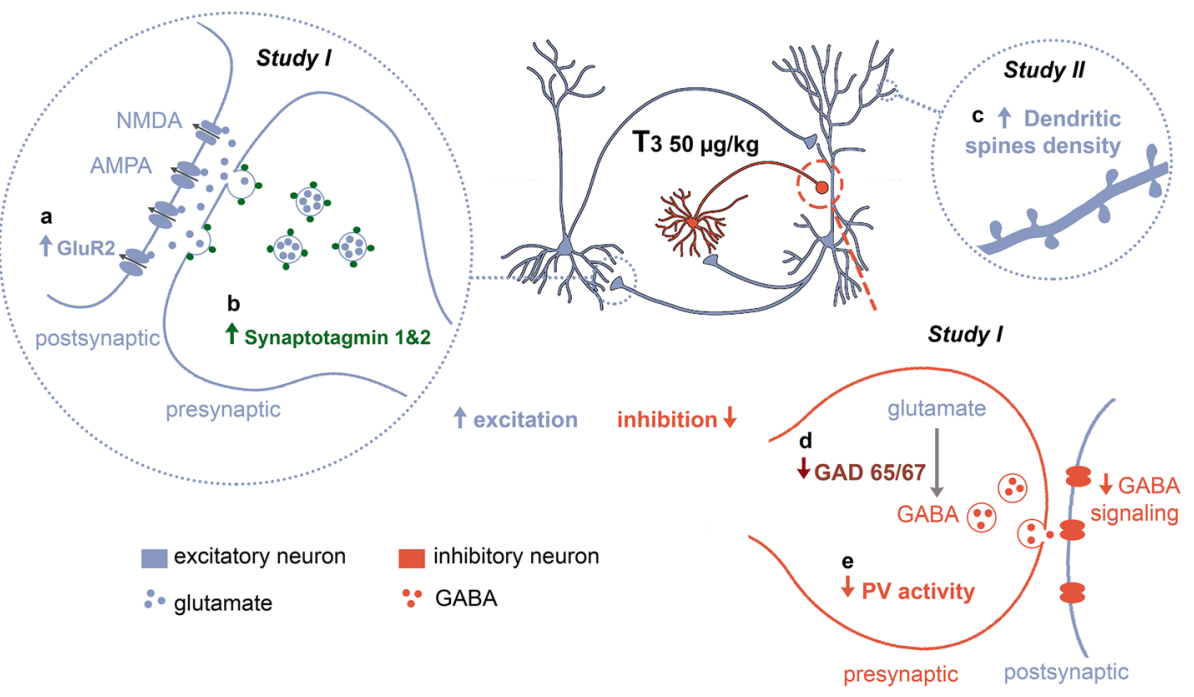

B. Acute effects of $\mathrm{T}_{3}$ after stroke

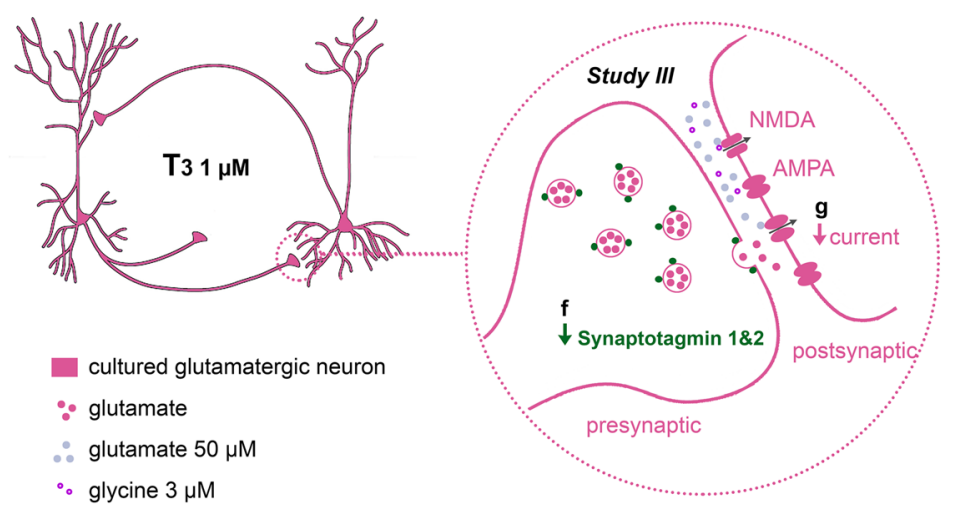

Fig. 7 Proposed mechanisms of homeostatic regulation of neurotransmission by $T_{3}$. (A) After photothrombosis (PT), administration of $T_{3} 50 \mu g / k g$ for 14 days modulates pathways during the recovery period after stroke involved in reorganization of neuronal circuits and synaptic plasticity, to balance excitation and inhibition ratio. a $T_{3}$ increases levels of post-synaptic glutamate receptor 2 (GluR2) subunit in AMPA receptors in the periinfarct area and $\mathbf{b}$ increases levels of synaptotagmin 1\&2, increasing the probability of neurotransmitter release. $\mathbf{c} \mathrm{T}_{3}$ increases dendritic spines density in the ipsilateral and contralateral regions. $\mathbf{d} \mathrm{T}_{3}$ decreases tonic GABAergic signaling in the peri-infarct area by a decrease in the levels of GAD 65/67 and e reduced parvalbumin (PV) activity. (B) In an acute model of cerebral ischemia and hyperexcitability, $\mathbf{f}$ in glutamatergic neurons pre-treated with $T_{3}$ at $1 \mu \mathrm{M}$ for $48 \mathrm{~h}$ there is a decrease in levels of synaptotagmin and $\mathbf{g} \mathrm{T}_{3}$ modulates neuron membrane properties with the balance of inward glutamate ligand-gated channels currents 
cultured glutamatergic neurons pre-treated for $48 \mathrm{~h}$ with $\mathrm{T}_{3} 1 \mu \mathrm{M}$. Interestingly, we found that glutamate evoked currents were significantly lower in neurons previously incubated with $T_{3}$. Similarly, in a previous study, $T_{3}$ at $10 \mu \mathrm{M}$ has been implicated in the reduction of miniature excitatory post-synaptic currents frequency and glutamate induced toxicity in hippocampal neurons [42]. Interestingly, we found that $\mathrm{T}_{3}$ recruits divergent mechanisms to achieve homeostasis in two different systems regarding synaptic network organization, i.e., in vitro and in vivo and dependent on the activation status of neurons and brain tissues, respectively. Important for stroke recovery, $\mathrm{T}_{3}$ could modulate synaptic neurotransmission to an optimal firing rate.

After an ischemic insult, synaptic glutamate signaling is depressed also due to tonic inhibition of neuronal circuits, which ultimately restricts the process of recovery $[8,15$, 80]. Modulation to shift the excitation - inhibition ratio by stimulation of glutamate signaling $[15,17]$ and reducing GABA inhibition $[1,15,16]$ in the motor and somatosensory cortex accelerates motor recovery in mice. GABAergic neurotransmission is mediated by cortical interneurons, a group of cells expressing calcium-binding proteins, including PV. In fact, a correlation between reduction of PV/ GABA cells and functional recovery in rodents subjected to stroke has been shown [86]. Also, different therapeutic approaches such as environment enrichment [29], benzodiazepine inverse agonist [1], but also intravenous infusion of human bone marrow mesenchymal stromal cells after transient MCAO [62] decreased cortical PV immunoreactivity or activity and were associated with enhanced recovery of lost neurological function. Treatment with $\mathrm{T}_{3}$ reduced the activity of PV immunoreactive cells in the peri-infarct area and in the contralateral hemisphere, without affecting the total number of $\mathrm{PV}^{+}$cells.

Concomitantly, in the peri-infarct area of animals treated with $\mathrm{T}_{3} 50 \mu \mathrm{g} / \mathrm{kg}$, expression levels of GAD 65/ 67 was significantly reduced, and directly GABA production. Our results are in accordance with studies describing an increased GAD activity and GABA uptake in neurons in hypothyroid state [34] and the finding that $\mathrm{T}_{3}$ administration inhibits GABA-induced $\mathrm{Cl}^{-}$currents [45]. Thus, the decrease in PV cortical activity may facilitate experience dependent plasticity and decrease GABA availability and tonic inhibition, and therefore contribute to restoration of neuronal networks.

Together, our findings reveal important implications of $\mathrm{T}_{3}$-mediated mechanisms in stroke recovery (Fig. 7). At the cellular and structural level, we demonstrated that $\mathrm{T}_{3}$ is involved in mechanisms of neuronal plasticity that collectively contributed to functional recovery following experimental stroke. Based on our findings it will be possible to develop specific approaches targeting $\mathrm{T}_{3}$ mediated mechanisms in the post-ischemic brain. Those may result in specific treatments to be tested in clinical trials.

\section{Supplementary information}

Supplementary information accompanies this paper at https://doi.org/10. 1186/s40478-019-0866-4.
Additional file 1. Supplementary Methods and Results.
Additional file 2. Rotating pole test mouse 1 selective sorting after photothrombosis.

Additional file 3. Rotating pole test mouse 1 after vehicle treatment at 14 days.

Additional file 4. Rotating pole test mouse 2 selective sorting after photothrombosis.

Additional file 5. Rotating pole test mouse 2 after $T_{3}$ treatment $(50 \mu \mathrm{g} / \mathrm{kg})$ at 14 days.

\section{Acknowledgements}

This work was supported by funds from the Health Sciences Research Center (CICS-UBI) through National Funds by FCT - Foundation for Science and Technology UID / Multi / 00709/2019 (CRS and IG); by a doctoral fellowship (SFRH/BD/104679/2014) from FCT (DT); partially supported by "Programa Operacional do Centro, Centro 2020" through the funding of the ICON project (Interdisciplinary Challenges on Neurodegeneration; CENTRO-010145-FEDER-000013) (ARC, CRS and IG)"; the Swedish Brain Fund; the Crafoord Foundation, Sveriges Stroke Riksförbundet; the Hans-Gabriel and Alice Trolle-Wachtmeister Foundation, The Alborada Research Fund; Sparbanksstiftelsen Färs \& Frosta and a regional grant - ALF-Skåne (TW and KR). Image acquisition for dendritic spine analysis was performed in the Microscopy facility of CICS-UBI, a node of PPBI (Portuguese Platform of Biolmaging): POCI-010145-FEDER-022122.

\section{Authors' contributions}

DT and KR designed the research; DT, JF, ARC, TT, EC and KR performed research studies. EE provided human post-mortem brain tissues. EC, TW, CRS, IG and KR provided funding and material for all the experiments. EC, CRS, IG and KR supervised the studies. DT wrote the paper with input from all authors. All authors read and approved the final manuscript.

\section{Funding}

Open access funding provided by Lund University.

\section{Competing interests}

The authors declare that they have no competing interests.

\section{Author details}

${ }^{1}$ Laboratory for Experimental Brain Research, Division of Neurosurgery, Department of Clinical Sciences, Lund University, BMC A13, S-22184 Lund, Sweden. ${ }^{2}$ CICS-UBI-Health Sciences Research Centre, Faculdade de Ciências da Saúde, Universidade da Beira Interior, Covilhã, Portugal. ${ }^{3}$ Division of Oncology and Pathology, Lund University Hospital, Lund, Sweden. ${ }^{4}$ LUBIN Lab - Lunds Laboratorium för Neurokirurgisk Hjärnskadeforskning, Division of Neurosurgery, Department of Clinical Sciences, Lund University, Lund, Sweden.

Received: 29 October 2019 Accepted: 8 December 2019

Published online: 21 December 2019

References

1. Alia C, Spalletti C, Lai S, Panarese A, Micera S, Caleo M (2016) Reducing GABA A-mediated inhibition improves forelimb motor function after focal cortical stroke in mice. Sci Rep 29:37823. https://doi.org/10.1038/srep37823

2. Anyetei-Anum CS, Roggero VR, Allison LA (2018) Thyroid hormone receptor localization in target tissues. J Endocrinol 237:R19-R34. https://doi.org/10. 1530/JOE-17-0708

3. Bárez-López S, Guadaño-Ferraz A (2017) Thyroid hormone availability and action during brain development in rodents. Front Cell Neurosci 11:1-7. https://doi.org/10.3389/fncel.2017.00240 
4. Benjamin EJ, Blaha MJ, Chiuve SE, Cushman M, Das SR, Deo R et al (2017) Heart disease and stroke Statistics'2017 update: a report from the American Heart Association. Circulation. 135(10):e146-e603. https://doi.org/10.1161/ CIR.0000000000000485.

5. Bernal J (2000) Thyroid hormones in brain development and function [updated 2015 Sep 2]. In: Feingold KR, Anawalt B, Boyce A et al (eds) Endotext. MDText.com, Inc., South Dartmouth, pp 1-136

6. Bhatt DH, Zhang S, Gan W-B (2009) Dendritic spine dynamics. Annu Rev Physiol 71:261-282. https://doi.org/10.1146/annurev.physiol.010908.163140

7. Biernaskie J (2004) Efficacy of rehabilitative experience declines with time after focal ischemic brain injury. J Neurosci 24:1245-1254. https://doi.org/10. 1523/JNEUROSCI.3834-03.2004

8. Boddington $\sqcup$, Reynolds JNJ (2017) Targeting interhemispheric inhibition with neuromodulation to enhance stroke rehabilitation. Brain Stimul 10: 214-222. https://doi.org/10.1016/j.brs.2017.01.006

9. Branco T, Staras K (2009) The probability of neurotransmitter release: variability and feedback control at single synapses. Nat Rev Neurosci 10: 373-383. https://doi.org/10.1038/nrn2634

10. Bredt DS, Nicoll RA (2003) AMPA receptor trafficking at excitatory synapses. Neuron 40:361-379. https://doi.org/10.1016/S0896-6273(03)00640-8

11. Brown CE, Boyd JD, Murphy TH (2010) Longitudinal in vivo imaging reveals balanced and branch-specific remodeling of mature cortical pyramidal dendritic arbors after stroke. J Cereb Blood Flow Metab 30:783-791. https:// doi.org/10.1038/jcbfm.2009.241

12. Brown CE, Li P, Boyd JD, Delaney KR, Murphy TH (2007) Extensive turnover of dendritic spines and vascular remodeling in cortical tissues recovering from stroke. J Neurosci 27:4101-4109. https://doi.org/10.1523/JNEUROSCl. 4295-06.2007

13. Brown CE, Wong C, Murphy TH (2008) Rapid morphologic plasticity of periinfarct dendritic spines after focal ischemic stroke. Stroke 39:1286-1291. https://doi.org/10.1161/STROKEAHA.107.498238

14. Carlson DJ, Strait KA, Schwartz HL, Oppenheimer JH (1994) Immunofluorescent localization of thyroid hormone receptor isoforms in glial cells of rat brain. Endocrinology 135:1831-1836. https://doi.org/10. 1210/endo.135.5.7525253

15. Carmichael ST (2012) Brain excitability in stroke: the yin and yang of stroke progression. Arch Neurol 69:161-167. https://doi.org/10.1001/archneurol. 2011.1175

16. Clarkson AN, Huang BS, Macisaac SE, Mody I, Carmichael ST (2010) Reducing excessive GABA-mediated tonic inhibition promotes functional recovery after stroke. Nature 468:305-309. https://doi.org/10.1038/ nature09511

17. Clarkson AN, Overman JJ, Zhong S, Mueller R, Lynch G, Carmichael ST (2011) AMPA receptor-induced local brain-derived Neurotrophic facto signaling mediates motor recovery after stroke. J Neurosci. https://doi.org/ 10.1523/JNEUROSCI.5780-10.2011

18. Cramer SC (2008) Repairing the human brain after stroke: I. mechanisms of spontaneous recovery. Ann Neurol 63:272-287. https://doi.org/10.1002/ana. 21393

19. Cramer SC (2018) Treatments to promote neural repair after stroke. J Stroke 20:57-60. https://doi.org/10.5853/jos.2017.02796

20. Crupi R, Paterniti I, Campolo M, Di Paola R, Cuzzocrea S, Esposito E (2013) Exogenous T3 administration provides neuroprotection in a murine model of traumatic brain injury. Pharmacol Res 70:80-89. https://doi.org/10.1016/j. phrs.2012.12.009

21. Dalise S, Ambrosio F, Modo M (2014) Adaptive plasticity and recovery in preclinical models of stroke. Arch Ital Biol 152:190-215. https://doi.org/10. 12871/00039829201442

22. Doyle KP, Suchland KL, Ciesielski TMP, Lessov NS, Grandy DK, Scanlan TS et al (2007) Novel thyroxine derivatives, thyronamine and 3iodothyronamine, induce transient hypothermia and marked neuroprotection against stroke injury. Stroke 38:2569-2576. https://doi. org/10.1161/STROKEAHA.106.480277

23. Dromerick AW, Edwardson MA, Edwards DF, Giannetti ML, Barth J, Brady KP et al (2015) Critical periods after stroke study: translating animal stroke recovery experiments into a clinical trial. Front Hum Neurosci 9:231. https:// doi.org/10.3389/fnhum.2015.00231

24. Duncan PW, Min Lai S, Keighley J (2000) Defining post-stroke recovery: implications for design and interpretation of drug trials. Neuropharmacology 39:835-841. https://doi.org/10.1016/S00283908(00)00003-4
25. Enright LE, Zhang S, Murphy TH (2007) Fine mapping of the spatial relationship between acute ischemia and dendritic structure indicates selective vulnerability of layer $V$ neuron dendritic tufts within single neurons in vivo. J Cereb Blood Flow Metab 27:1185-1200. https://doi.org/10.1038/sj. jcbfm.9600428

26. Feigin VL, Norrving B, Mensah GA (2017) Global burden of stroke. Circ Res 120:439-448. https://doi.org/10.1161/CIRCRESAHA.116.308413

27. Genovese T, Impellizzeri D, Ahmad A, Cornelius C, Campolo M, Cuzzocrea S et al (2013) Post-ischaemic thyroid hormone treatment in a rat model of acute stroke. Brain Res 1513:92-102. https://doi.org/10.1016/j.brainres.2013. 03.001

28. Gothié JD, Demeneix B, Remaud S (2017) Comparative approaches to understanding thyroid hormone regulation of neurogenesis. Mol Cell Endocrinol 459:104-115. https://doi.org/10.1016/j.mce.2017.05.020

29. Hakon J, Quattromani MJ, Sjölund C, Tomasevic G, Carey L, Lee JM et al (2018) Multisensory stimulation improves functional recovery and restingstate functional connectivity in the mouse brain after stroke. Neurolmage Clin 17:717-730. https://doi.org/10.1016/j.nicl.2017.11.022

30. Harris KM, Jensen FE, Tsao B (1992) Three-dimensional structure of dendritic spines and synapses in rat hippocampus (CA1) at postnatal day 15 and adult ages: implications for the maturation of synaptic physiology and longterm potentiation. J Neurosci 12:2685-2705

31. Huang SY, Chang CH, Hung HY, Lin YW, Lee EJ (2018) Neuroanatomical and electrophysiological recovery in the contralateral intact cortex following transient focal cerebral ischemia in rats. Neurol Res 40:130-138. https://doi. org/10.1080/01616412.2017.1411454

32. Isaac JTR, Ashby M, McBain CJ (2007) The role of the GluR2 subunit in AMPA receptor function and synaptic plasticity. Neuron 54:859-871. https:// doi.org/10.1016/j.neuron.2007.06.001

33. Jones TA, Adkins DL (2015) Motor system reorganization after stroke: stimulating and training toward perfection. Physiology 30:358-370. https:// doi.org/10.1152/physiol.00014.2015

34. Kalaria RN, Prince AK (1985) Effects of thyroid deficiency on the development of cholinergic, GABA, dopaminergic and glutamate neuron markers and DNA concentrations in the rat corpus striatum. Int J Dev Neurosci 3:655-666. https://doi.org/10.1016/07365748(85)90056-5

35. Kapoor R, Fanibunda SE, Desouza LA, Guha SK, Vaidya VA (2015) Perspectives on thyroid hormone action in adult neurogenesis. J Neurochem 133:599-616. https://doi.org/10.1111/jnc.13093

36. Kim JT, Fonarow GC, Smith EE, Reeves MJ, Navalkele DD, Grotta JC et al (2017) Treatment with tissue plasminogen activator in the Golden hour and the shape of the 4.5-hour time-benefit curve in the National United States get with the Guidelines-Stroke Population. Circulation 135:128-139. https:// doi.org/10.1161/CIRCULATIONAHA.116.023336

37. Knecht S, Hesse S, Oster P (2011) Rehabilitation after stroke. Dtsch Arztebl Int 108:600-606. https://doi.org/10.3238/arztebl.2011.0600

38. Kuric E, Ruscher K (2014) Reduction of rat brain CD8+ T-cells by levodopa/ benserazide treatment after experimental stroke. Eur J Neurosci 40:24632470. https://doi.org/10.1111/ejn.12598

39. Kwon SE, Chapman ER (2011) Synaptophysin regulates the kinetics of synaptic vesicle endocytosis in central neurons. Neuron 70:847-854. https:// doi.org/10.1016/j.neuron.2011.04.001

40. Li J, Donangelo I, Abe K, Scremin O, Ke S, Li F et al (2017) Thyroid hormone treatment activates protective pathways in both in vivo and in vitro models of neuronal injury. Mol Cell Endocrinol 452:120-130. https://doi.org/10.1016/ j.mce.2017.05.023

41. Liu YY, Brent GA (2018) Thyroid hormone and the brain: mechanisms of action in development and role in protection and promotion of recovery after brain injury. Pharmacol Ther 186:176-185. https://doi.org/10.1016/j. pharmthera.2018.01.007

42. Losi G, Garzon G, Puia G (2008) Nongenomic regulation of glutamatergic neurotransmission in hippocampus by thyroid hormones. Neuroscience 151 155-163. https://doi.org/10.1016/j.neuroscience.2007.09.064

43. Lourbopoulos A, Mourouzis I, Karapanayiotides T, Nousiopoulou E, Chatzigeorgiou S, Mavridis T et al (2014) Changes in thyroid hormone receptors after permanent cerebral ischemia in male rats. J Mol Neurosci 54: 78-91. https://doi.org/10.1007/s12031-014-0253-3

44. Maia AL, Kim BW, Huang SA, Harney JW, Larsen PR (2005) Type 2 iodothyronine deiodinase is the major source of plasma T3 in euthyroid humans. J Clin Invest 115:2524-2533. https://doi.org/10.1172/JCI25083 
45. Martin JV, Williams DB, Fitzgerald RM, Im HK, Vonvoigtlander PF (1996) Thyroid hormonal modulation of the binding and activity of the GABA(a) receptor complex of brain. Neuroscience 73:705-713. https://doi.org/10. 1016/0306-4522(96)00052-8

46. Mdzinarishvili A, Sutariya V, Talasila PK, Geldenhuys WJ, Sadana P (2013) Engineering triiodothyronine (T3) nanoparticle for use in ischemic brain stroke. Drug Deliv Transl Res 3:309-317. https://doi.org/10.1007/s13346012-0117-8

47. Mullur R, Liu YY, Brent GA (2014) Thyroid hormone regulation of metabolism. Physiol Rev 94:355-382. https://doi.org/10.1152/physrev.00030.2013

48. Overman JJ, Carmichael ST (2014) Plasticity in the injured brain: more than molecules matter. Neuroscientist 20:15-28. https://doi.org/10.1177/ 1073858413491146

49. Peisker T, Koznar B, Stetkarova I, Widimsky P (2017) Acute stroke therapy: a review. Trends Cardiovasc Med 27:59-66. https://doi.org/10.1016/j.tcm.2016. 06.009

50. Pekna M, Pekny M, Nilsson M (2012) Modulation of neural plasticity as a basis for stroke rehabilitation. Stroke 43:2819-2828. https://doi.org/10.1161/ STROKEAHA.112.654228

51. Pérez-Otaño I, Ehlers MD (2005) Homeostatic plasticity and NMDA receptor trafficking. Trends Neurosci 28:229-238. https://doi.org/10.1016/ j.tins.2005.03.004

52. Pozo K, Goda Y (2010) Unraveling mechanisms of homeostatic synaptic plasticity. Neuron 66:337-351. https://doi.org/10.1016/j.neuron.2010.04.028

53. Quattromani MJ, Cordeau P, Ruscher K, Kriz J, Wieloch T (2014) Enriched housing down-regulates the toll-like receptor 2 response in the mouse brain after experimental stroke. Neurobiol Dis 66:66-73. https://doi.org/10. 1016/j.nbd.2014.02.010

54. Que M, Schiene K, Witte OW, Zilles K (1999) Widespread up-regulation of $\mathrm{N}$-methyl-D-aspartate receptors after focal photothrombotic lesion in rat brain. Neurosci Lett 273:77-80. https://doi.org/10.1016/S03043940(99)00598-4

55. Rami A, Krieglstein J (1992) Thyroxine attenuates hippocampal neuronal damage caused by ischemia in the rat. Life Sci 50:645-650. https://doi.org/ 10.1016/0024-3205(92)90251-J

56. Remaud S, Gothié JD, Morvan-Dubois G, Demeneix BA (2014) Thyroid hormone signaling and adult neurogenesis in mammals. Front Endocrinol (Lausanne) 5:62. https://doi.org/10.3389/fendo.2014.00062

57. Rickhag M, Deierborg T, Patel S, Ruscher K, Wieloch T (2008) Apolipoprotein $D$ is elevated in oligodendrocytes in the peri-infarct region after experimental stroke: influence of enriched environment. J Cereb Blood Flow Metab 28:551-562. https://doi.org/10.1038/sj.jcbfm.9600552

58. Rodriguez A, Ehlenberger DB, Dickstein DL, Hof PR, Susan L (2008) Automated Three-Dimensional Detection and Shape Classification of Dendritic Spines from Fluorescence Microscopy Images. PLoS One 3:e1997. https://doi.org/10.1371/journal.pone.0001997

59. Ruscher K, Freyer D, Karsch M, Isaev N, Megow D, Sawitzki B et al (2002) Erythropoietin is a paracrine mediator of ischemic tolerance in the brain evidence from an in vitro model. J Neurosci 22:10291-10301. https://doi. org/10.1523/jneurosci.22-23-10291.2002

60. Ruscher K, Johannesson E, Brugiere E, Erickson A, Rickhag M, Wieloch T (2009) Enriched environment reduces apolipoprotein $E$ (ApoE) in reactive astrocytes and attenuates inflammation of the peri-infarct tissue after experimental stroke. J Cereb Blood Flow Metab 29:1796-1805. https://doi. org/10.1038/jcbfm.2009.96

61. Sadana P, Coughlin L, Burke J, Woods R, Mdzinarishvili A (2015) Anti-edema action of thyroid hormone in MCAO model of ischemic brain stroke: possible association with AQP4 modulation. J Neurol Sci 354:37-45. https:// doi.org/10.1016/j.jns.2015.04.042

62. Sammali E, Alia C, Vegliante G, Colombo V, Giordano N, Pischiutta F et al (2017) Intravenous infusion of human bone marrow mesenchymal stromal cells promotes functional recovery and neuroplasticity after ischemic stroke in mice. Sci Rep 7:6962. https://doi.org/10.1038/s41598-017-07274-w

63. Saraiva C, Talhada D, Rai A, Ferreira R, Ferreira L, Bernardino L et al (2018) MicroRNA-124-loaded nanoparticles increase survival and neuronal differentiation of neural stem cells in vitro but do not contribute to stroke outcome in vivo. PLoS One 13:e0193609. https://doi.org/10.1371/journal. pone.0193609

64. Schindelin J, Arganda-Carreras I, Frise E, Kaynig V, Longair M, Pietzsch T et a (2012) Fiji: an open-source platform for biological-image analysis. Nat Methods 9:676-682
65. Schroeter M, Jander S, Stoll G (2002) Non-invasive induction of focal cerebral ischemia in mice by photothrombosis of cortical microvessels: characterization of inflammatory responses. J Neurosci Methods 117:43-49. https://doi.org/10.1016/S0165-0270(02)00072-9

66. Seung HJ, Hyeong SC, Ki JK, Qing ZL, Sung KW (2009) Electrophysiological characterization of AMPA and NMDA receptors in rat dorsal striatum. Korean J Physiol Pharmacol 13:209-214. https://doi.org/10.4196/kjpp.2009. 13.3.209

67. Soundarapandian MM, Wei HT, Peng PL, Zervos AS, Lu YM (2005) AMPA receptor subunit GluR2 gates injurious signals in ischemic stroke. Mol Neurobiol 32:145-155. https://doi.org/10.1385/MN:32:2:145

68. Südhof TC (2012) Calcium control of neurotransmitter release. Cold Spring Harb Perspect Biol 4:a011353. https://doi.org/10.1101/cshperspect.a011353

69. Südhof TC (2013) A molecular machine for neurotransmitter release: Synaptotagmin and beyond. Nat Med 19:1227-1231. https://doi.org/10. 1038/nm.3338

70. Swanson RA, Morton MT, Tsao-Wu G, Savalos RA, Davidson C, Sharp FR (1990) A semiautomated method for measuring brain infarct volume. J Cereb Blood Flow Metab 10:290-293. https://doi.org/10. 1038/jcbfm.1990.47

71. Talhada D, Santos CRA, Gonçalves I, Ruscher K (2019) Thyroid hormones in the brain and their impact in recovery mechanisms after stroke. Front Neurol 10:1103. https://doi.org/10.3389/fneur.2019.01103

72. Tennant KA, Adkins DL, Donlan NA, Asay AL, Thomas N, Kleim JA et al (2011) The organization of the forelimb representation of the C57BL/6 mouse motor cortex as defined by intracortical microstimulation and cytoarchitecture. Cereb Cortex 21:865-876. https://doi.org/10.1093/ cercor/bha159

73. Thompson CC, Potter GB (2000) Thyroid hormone action in neural development. Cereb Cortex 10:939-945. https://doi.org/10.1093/cercor/ 10.10.939

74. Tu HM, Kim SW, Salvatore D, Bartha T, Legradi G, Larsen PR et al (1997) Regional distribution of type 2 thyroxine deiodinase messenger ribonucleic acid in rat hypothalamus and pituitary and its regulation by thyroid hormone. Endocrinology 138:3359-3368. https://doi.org/10.1210/ endo.138.8.5318

75. Turrigiano G (2011) Too many cooks? Intrinsic and synaptic homeostatic mechanisms in cortical circuit refinement. Annu Rev Neurosci 34:89-103. https://doi.org/10.1146/annurev-neuro-060909-153238

76. Turrigiano G (2012) Homeostatic synaptic plasticity: local and global mechanisms for stabilizing neuronal function. Cold Spring Harb Perspect Biol 4:a005736. https://doi.org/10.1101/cshperspect.a005736

77. Turrigiano GG, Nelson SB (2004) Homeostatic plasticity in the developing nervous system. Nat Rev Neurosci 5:97-107. https://doi.org/10.1038/nrn1327

78. Walsh RN, Cummins RA (1976) The open-field test: a critical review. Psychol Bull 83:482-504. https://doi.org/10.1037/0033-2909.83.3.482

79. Walter HL, van der Maten G, Antunes AR, Wieloch T, Ruscher K (2015) Treatment with AMD3100 attenuates the microglial response and improves outcome after experimental stroke. J Neuroinflammation 12:24. https://doi. org/10.1186/s12974-014-0232-1

80. Ward NS (2017) Restoring brain function after stroke - bridging the gap between animals and humans. Nat Rev Neurol 13:244-255. https://doi.org/ 10.1038/nrneurol.2017.34

81. Watson BD, Dietrich WD, Busto R, Wachtel MS, Ginsberg MD (1985) Induction of reproducible brain infarction by photochemically initiated thrombosis. Ann Neurol 17:497-504. https://doi.org/10.1002/ana. 410170513

82. Wieloch T, Nikolich K (2006) Mechanisms of neural plasticity following brain injury. Curr Opin Neurobiol 16:258-264. https://doi.org/10.1016/j.conb.2006. 05.011

83. Yang HY, Sun CP, Jia XM, Gui L, Zhu DF, Ma WQ (2012) Effect of thyroxine on SNARE complex and synaptotagmin-1 expression in the prefrontal cortex of rats with adult-onset hypothyroidism. J Endocrinol Investig 35 312-316. https://doi.org/10.3275/7767

84. Yasuda R (2017) Biophysics of biochemical signaling in dendritic spines: implications in synaptic plasticity. Biophys J 113:2152-2159. https://doi.org/ 10.1016/j.bpj.2017.07.029

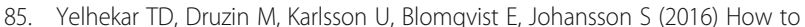
properly measure a current-voltage relation? -interpolation vs. ramp methods applied to studies of GABAA receptors. Front cell Neurosci 10:10. https://doi.org/10.3389/fncel.2016.00010 
86. Zeiler SR, Gibson EM, Hoesch RE, Li MY, Worley PF, O'Brien RJ et al (2013) Medial premotor cortex shows a reduction in inhibitory markers and mediates recovery in a mouse model of focal stroke. Stroke 44:483-489. https://doi.org/10.1161/STROKEAHA.112.676940

87. Zhang S (2005) Rapid reversible changes in dendritic spine structure in vivo gated by the degree of ischemia. J Neurosci 25:5333-5338. https://doi.org/ 10.1523/JNEUROSCl.1085-05.2005

\section{Publisher's Note}

Springer Nature remains neutral with regard to jurisdictional claims in published maps and institutional affiliations.

Ready to submit your research? Choose BMC and benefit from:

- fast, convenient online submission

- thorough peer review by experienced researchers in your field

- rapid publication on acceptance

- support for research data, including large and complex data types

- gold Open Access which fosters wider collaboration and increased citations

- maximum visibility for your research: over $100 \mathrm{M}$ website views per year

At BMC, research is always in progress.

Learn more biomedcentral.com/submissions 